\title{
Einleitung: Tradition und Moderne. Die Peking Universität, der 4. Mai 1919 und der deutsch-chinesische Ideenaustausch
}

\section{Red Building}

„Die Transformationen, die sich in China während der vergangenen einhundert Jahre ereignet haben, waren wohl wirkmächtiger als sämtliche Veränderungen des zurückliegenden Jahrtausends zusammengenommen. Seit der Neue-KulturBewegung hat die chinesische Gesellschaft noch nie dagewesene strukturelle und ideologische Umwälzungen durchgemacht“ (Old Nation New Mission, 206). ${ }^{1}$ Die prägnanten Worte sind dem Nachwort des offiziellen Katalogs Old Nation New Mission entnommen, der anlässlich der Pekinger Ausstellung zum einhundertsten Jahrestag der „Neue-Kultur-Bewegung“ erschienen ist. Der Ausstellungsort selbst und dessen Lage in der Stadtmitte Pekings bestätigen eindrucksvoll den Befund des radikalen Bruchs in der modernen chinesischen Geschichte. Eingerichtet nämlich wurde das Museum der Neue-Kultur-Bewegung im ehemaligen Hauptgebäude der Peking Universität, aufgrund seiner Konstruktion aus roten Ziegelsteinen „Red Building“ genannt. Auf wundersame Weise hat sich das historische Gebäude über all die gewaltigen historischen Brüche der vergangenen einhundert Jahre, über Revolutionen, Kriege, Bürgerkriege und Stadtumbauten hinweg in seinem ursprünglichen Zustand erhalten.

In jenem roten Backsteingebäude in unmittelbarer Nähe des Kaiserpalastes in der Stadtmitte hatte Chinas bis zum heutigen Tage namhafteste Bildungseinrichtung seit 1918 ihren Sitz. Gegründet als Kaiserliche Universität im Jahre 1898 im Rahmen der Reformen der Qing-Dynastie, nach der Xinhai-Revolution und der Abdankung des Kaiserhauses in Nationale Universität umbenannt, zog sie 1953, vier Jahre nach der Gründung der Volksrepublik, nun unter dem Namen Peking Universität (Beida), in den Bezirk Haidian im Nordwesten Pekings um. Nicht nur aufgrund ihres ursprünglichen Standorts im Regierungsviertel, sondern in einem allgemeinen intellektuellen und politischen Verständnis rückte die Peking Universität mit Beginn des 20. Jahrhunderts ins Zentrum der mit dem Modernisierungsprozess verbundenen historischen Ereignisse vor.

1 Englischsprachige Zitate in diesem Beitrag wurden vom Verfasser ins Deutsche übersetzt. 
Der in China seither und bis zum heutigen Tag erklingende Cantus firmus der Gesellschafts- und Bildungspolitik ist eine Variation über die Begriffe „Modernisierung“ und „Moderne“. Davon nicht zu trennen ist das wechselvolle, während der neueren chinesischen Geschichte phasenweise radikal polemische Verhältnis von Moderne und Überlieferung. Der Beginn der Moderne steht in China im Zeichen des Zusammenbruchs der jahrhundertealten Qing- bzw. Mandschu-Dynastie und der im Gefolge dieser epochalen Wende einsetzenden, fast vierzigjährigen Krisen-, Kriegs- und Bürgerkriegszeit, die, in einem formellen staatspolitischen Verständnis jedenfalls, erst mit Maos Ausrufung der Volksrepublik 1949 enden sollte, der dann aber womöglich noch gewaltigere Umbrüche während der 1950er und 1960er Jahre erst noch folgen, also insbesondere der „Große Sprung nach vorn“ (1958-1961) und die „Große proletarische Kulturrevolution“(1966-1976).

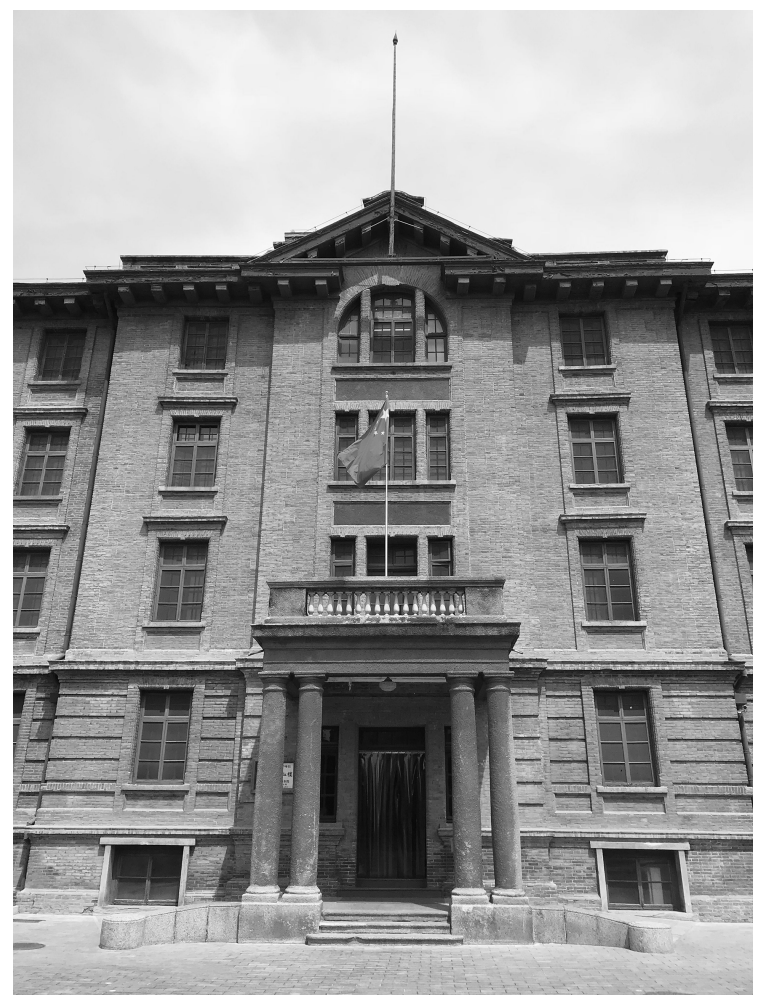

Abb. 2: Das „Red Building“ heute. 


\section{Traditionskritik und Bildungsreform}

Das alte Bildungssystem der überlieferten Gelehrsamkeit, das orientiert war auf die zentrale, für die Beamtenlaufbahn erforderliche Staatsprüfung, die vor allem die Kenntnis der Klassiker der chinesischen Literatur in der literarischen Hochsprache in exakt festgelegter, orthodoxer Auslegung voraussetzte, war 1905 noch vom zunehmend unter Modernisierungsdruck geratenen Kaiserhaus reformiert worden. Es wurde zugleich ein neues Schul- und Hochschulsystem, nicht selten nach westlichem Vorbild, aufgebaut. In diesen Zusammenhang gehört die Gründung der Peking Universität im Jahre 1898. Der Reformprozess im Bildungswesen wurde dann nach der Xinhai-Revolution 1911 systematisch und in großem Umfang fortgesetzt. Jene bereits im ausgehenden 19. Jahrhundert anhebenden und erst recht in der Folge des Sturzes der Mandschu-Dynastie an Dynamik gewinnenden Modernisierungsbestrebungen, die zunächst auf Sprache, Literatur, Schul- und Hochschulbildung bezogen waren und einhergingen mit einer zunehmend polemischer werdenden Kritik am klassischen konfuzianischen Bildungskanon, werden gemeinhin in der chinesischen Geschichtsschreibung unter dem Begriff „Neue-Kultur-Bewegung“ zusammengefasst. Die Peking Universität entwickelte sich nach der Ausrufung der Republik im Jahre 1912 zügig zum intellektuellen und dann auch institutionellen Mittelpunkt der Neue-Kultur-Bewegung (vgl. SchmidtGlintzer 2008, 151-193).

Der Umbruch im Bildungssystem fand damals nicht zuletzt auch darin seinen Ausdruck, dass zahlreiche junge Chinesen zum Studium ins Ausland, nach Europa, Amerika, insbesondere aber nach Japan gingen. In Japan war seit Mitte des 19. Jahrhunderts der Modernisierungsprozess nach westlichem Vorbild in vollem Gange. Kompromisslos hatte die Meiji-Restauration mit den jahrhundertealten japanischen Herrschafts- und Gesellschaftsstrukturen gebrochen, um eine technische und industrielle Modernisierung in Gang zu bringen und zugleich Infrastruktur, Militär und Verwaltung nach europäischen und amerikanischen Vorbildern aufzubauen. Vorausgegangen war der epochalen Wende die Erfahrung der hoffnungslosen militärischen Unterlegenheit Japans, als 1854 unter dem Druck der amerikanischen Kriegsschiffe zunächst die Häfen und dann das ganze Land den westlichen ökonomischen Interessen geöffnet werden mussten. $\mathrm{Zu}$ dem japanischen Modernisierungsplan, der in Reaktion auf diese militärische und politische Niederlage ins Werk gesetzt wurde, zählte als besonders folgenreiche Maßnahme - die konsequente Übernahme der westlichen Standards im Bildungs- und Wissenschaftsbereich.

Als dann während der ersten beiden Jahrzehnte des 20. Jahrhunderts chinesische Studenten in größerer Zahl nach Japan gingen, wurde an den Hochschulen dieses Landes, vor allem in den Naturwissenschaften, schon auf dem 
neuesten Stand der Wissenschaften unterrichtet. Dort war nicht nur die Lektüre der europäischen und amerikanischen Lehrbücher - in den medizinischen Fächern waren es insbesondere die deutschen Fachbücher - ein wichtiger Gegenstand des Studiums. Hier begegneten die chinesischen Studenten desgleichen und mitunter schon in japanischen Übersetzungen der Literatur- und Philosophiegeschichte des Westens. Kehrten sie dann am Ende ihrer Studienzeit mit solchen Erfahrungen nach China zurück, schlossen sie sich dort in der Regel jenen Kreisen traditionskritischer Intellektueller an, die unter dem Eindruck der politischen Demütigungen des alten kaiserlichen Chinas in der Auseinandersetzung mit den Kolonialmächten und insbesondere im Konflikt mit Japan eine fundamentale politische und kulturelle Modernisierung Chinas gefordert hatten.

Es war bezeichnend für die widerspruchsvolle historische Situation Chinas, dass sich die chinesischen Reformkräfte an der - nun gerade durch Japan vermittelten - westlichen Moderne orientierten, um auf diesem Wege die chinesische „Selbststärkung“ zu befördern und der Auseinandersetzung mit der westlichen und japanischen Fremdherrschaft gewachsen zu sein. Zur Parallelität des historischen Geschehens in Japan und China zählt daher auch der seit der Krise der Qing-Dynastie in China mit zunehmender Heftigkeit hervorbrechende Konflikt zwischen den konservativen Verteidigern der alten kaiserlichen, konfuzianisch geprägten Ordnung und den dagegen rebellierenden Modernisierern. Hatte doch eine Querelle des Anciens et des Modernes in ähnlichen Konstellationen zuvor bereits das japanische Modernisierungsprojekt begleitet.

\section{Kultur und Politik: 4. Mai 1919}

Vergleichbar sind auch die historischen Erfahrungen im Hintergrund der chinesischen Modernisierungsbestrebungen und der mit ihnen einhergehenden Reformdebatte. Die Niederlage im Opiumkrieg gegen die technisch weit überlegenen englischen Truppen sowie die in der Folge von den Kolonialmächten diktierten „Ungleichen Verträge“ (1842), die die Öffnung des chinesischen Marktes für westliche Waren und Wirtschaftsaktivitäten erzwangen, gehörten im kollektiven politischen Gedächtnis Chinas zu den traumatischen Erinnerungen, die bis weit ins 20. Jahrhundert virulent blieben. Zur gleichen Kette der demütigenden Erfahrungen einer technischen und militärisch-organisatorischen Unterlegenheit zählen die Niederlage im Chinesisch-Japanischen Krieg (1894/1895) sowie die dem Boxeraufstand im Jahre 1900 folgenden, eine Spur der Verwüstung hinterlassenden sogenannten „Strafaktionen“ der westlichen Alliierten. Schließlich gesellten sich 
1919 zu den wirkmächtigen politischen Enttäuschungen Chinas die Ergebnisse der Versailler Friedensverhandlungen, die im Widerspruch zum Selbstbestimmungsprogramm des amerikanischen Präsidenten Wilson das ehemalige Pachtgebiet des Kriegsverlierers Deutschland auf der Halbinsel Shandong keineswegs China, sondern Japan zusprachen sowie darüber hinaus die im wirtschaftlichen Interesse der Westmächte liegenden Bestimmungen der „Ungleichen Verträge“ den Anspruch etwa auf die westlichen Pachtgebiete und Freihäfen, darunter Hongkong und Macau - mitnichten außer Kraft setzten (zu den sogenannten „Schutz- und Pachtgebieten“ der Kolonialmächte in China, insbesondere zur deutschen „Musterkolonie“ Kiautchou, vgl. den Beitrag von Martin Heger im vorliegenden Band).

In der Empörung über diese Fortsetzung des Imperialismus des Westens nehmen die zunächst traditionskritischen Reformbemühungen insbesondere an der Peking Universität die politische Gestalt einer nationalen Protestbewegung an, die unter dem Namen „4.-Mai-Bewegung“ oder auch „4.-Mai-Revolution“ in die Geschichte eingeht. Die „4.-Mai-Bewegung“ erhält ihren Namen, weil sie sich öffentlich zum ersten Mal am 4. Mai 1919 formierte in einer Demonstration der Studenten mehrerer Pekinger Universitäten und Hochschulen gegen die genannten Bestimmungen des Versailler Vertrages und gegen die in den Augen der Protestierenden untaugliche chinesische Verteidigungspolitik. Ihren Ausgang nahm

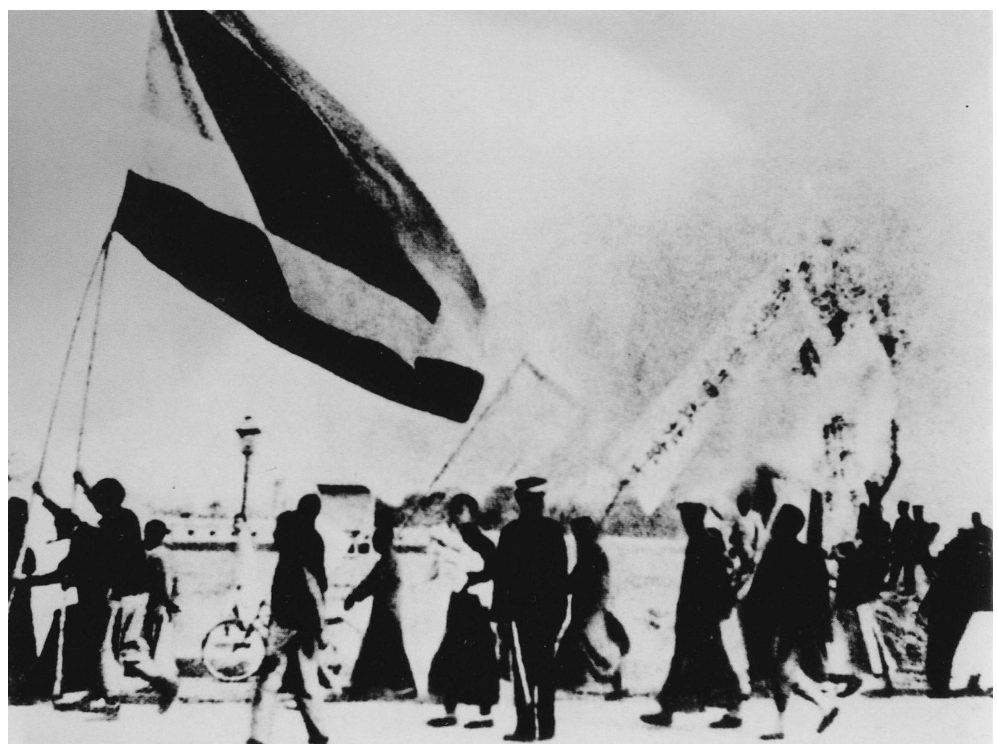

Abb. 3: Protestzug von Studierenden am 4. Mai 1919. 
die Kundgebung an der Peking Universität (vgl. Chow 1967, 99-117; zum 4. Mai 1919 im allgemeinen historischen und weltpolitischen Horizont vgl. den Beitrag von Arnd Bauerkämper im vorliegenden Band).

Gleichsam als Bühnenbild des für die moderne Geschichte Chinas so bedeutsamen historischen Moments hat man im ehemaligen Hauptgebäude dieser Hochschule, im Red Building, einen Raum mit solchen Fahnen und Transparenten eingerichtet, die den bedruckten Stoffen und bemalten Tüchern nachempfunden sind, die die Demonstranten damals mit sich führten. Die Spruchbänder, auf denen sie die volle Souveränität Chinas, die Rückgabe der Pachtgebiete und der damit verbundenen Handelsprivilegien, die Zurückweisung der japanischen Ansprüche bzw. die Verweigerung der Unterzeichnung des Versailler Vertrags forderten, bringen drastisch die Politisierung der ursprünglich intellektuellen Bewegung für eine Neue Kultur zum Ausdruck.

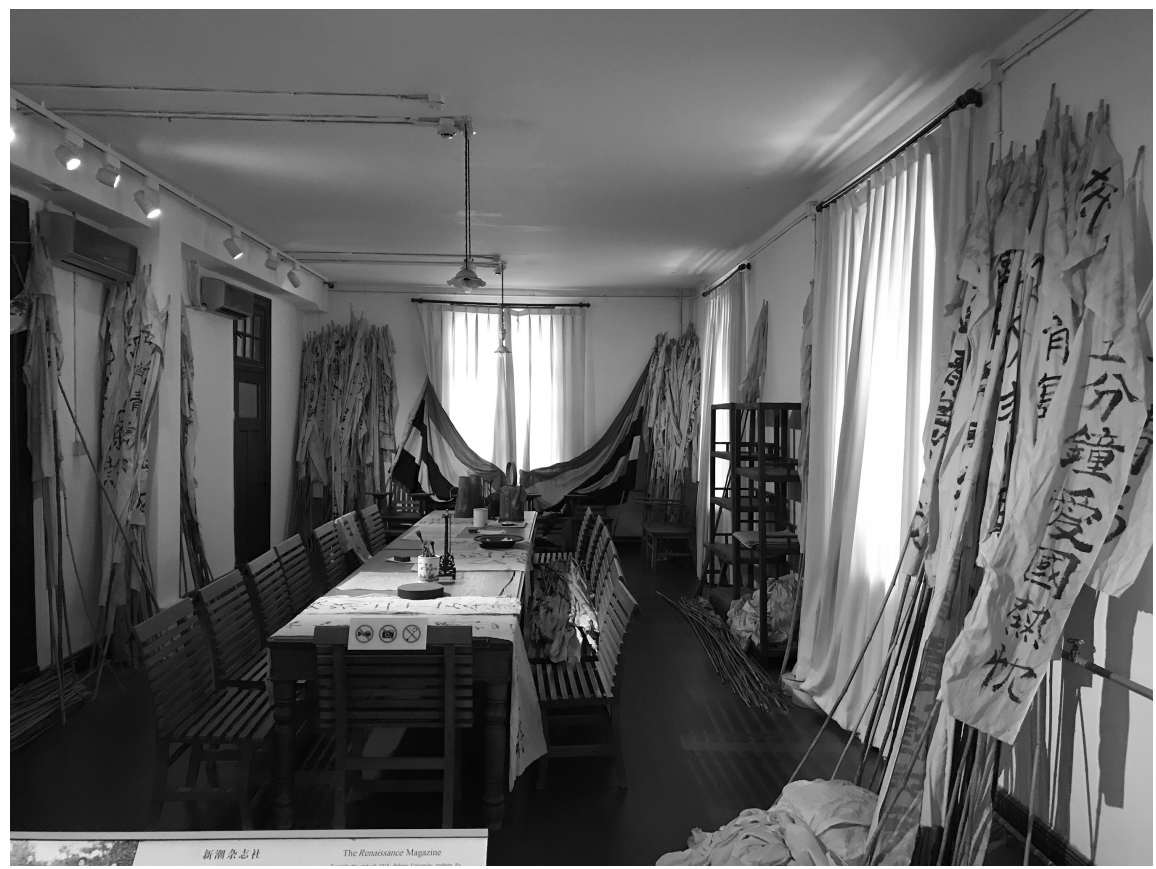

Abb. 4: Historische Fahnen und Transparente im „Red Building“.

Solchermaßen verbinden sich in der Demonstration des 4. Mai endgültig die kulturellen mit den politischen Themen. Fortan ist der Protest gegen den westlichen und japanischen Imperialismus nicht mehr zu trennen von der Selbstkri- 
tik der kulturellen, insbesondere konfuzianischen Überlieferung Chinas, die nunmehr als eine der wesentlichen Ursachen für die politische und ökonomische - und militärische! - Schwäche des Landes in der Auseinandersetzung mit den Kolonialmächten angesehen wird. Auf diese Weise gibt der 4. Mai 1919 der Neue-Kultur-Bewegung einen dezidiert politischen Gehalt, der dann während der folgenden Etappen des historischen Prozesses eine revolutionäre Dynamik entfalten wird.

\section{Cai Yuanpei}

Wie es die erhaltenen Fotografien des Ereignisses zeigen, führte der Demonstrationszug am 4. Mai 1919 zunächst vor das Tor des himmlischen Friedens an der Südseite der verbotenen Stadt im Zentrum Pekings und mithin zu jenem bedeutungsschweren Punkt im urbanen Terrain, der von diesem Tag an zum Schicksalsort der chinesischen Geschichte des 20. Jahrhunderts und des sie prägenden Konflikts zwischen Überlieferung und Moderne werden sollte. Als die Protestierenden daraufhin in das in der östlichen Nachbarschaft gelegene Botschaftsviertel weiterzogen, kam es zu heftigen Auseinandersetzungen mit Angehörigen der chinesischen Regierung, der man eine viel zu nachgiebige Verhandlungsführung in Versailles vorwarf.

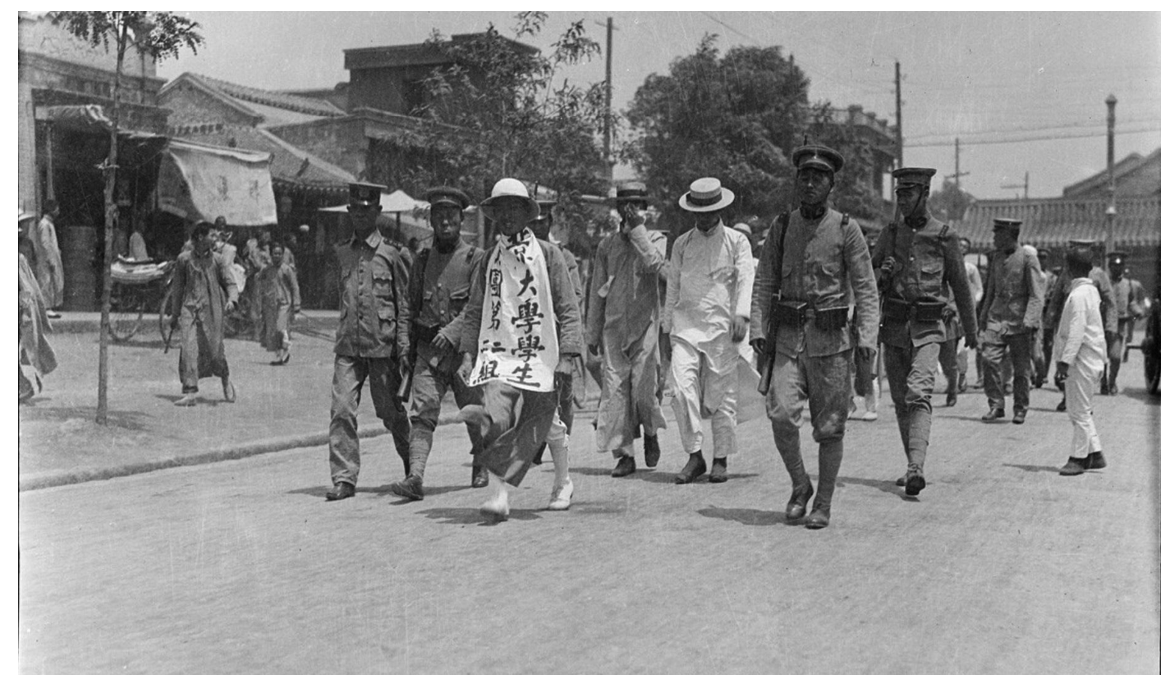

Abb. 5: Demonstrierende Studenten am 4. Mai 1919 werden von der Polizei abgeführt. 
Zahlreiche Demonstranten wurden verhaftet, was wiederum Cai Yuanpei, den Präsidenten der Peking Universität, dazu veranlasste, aus Protest gegen die Arretierung der Studenten von seinem Amt zurückzutreten. In der Folge der Ereignisse schlossen sich allenthalben in den größeren Städten Chinas Geschäftsleute, Angestellte und Arbeiter den Forderungen der 4.-Mai-Aktivisten an, in Shanghai wurde der Generalstreik ausgerufen. Die Auseinandersetzungen endeten schließlich damit, dass die chinesische Delegation in Versailles den Vertrag nicht unterschrieb, die festgesetzten Studenten wieder freikamen und Cai Yuanpei als Präsident in sein Amt an der Peking Universität zurückkehrte.

Seit 1917 stand Cai Yuanpei (1868-1940) an der Spitze der Hochschule, die er konsequent als eine moderne Wissenschaftsinstitution aufbaute.

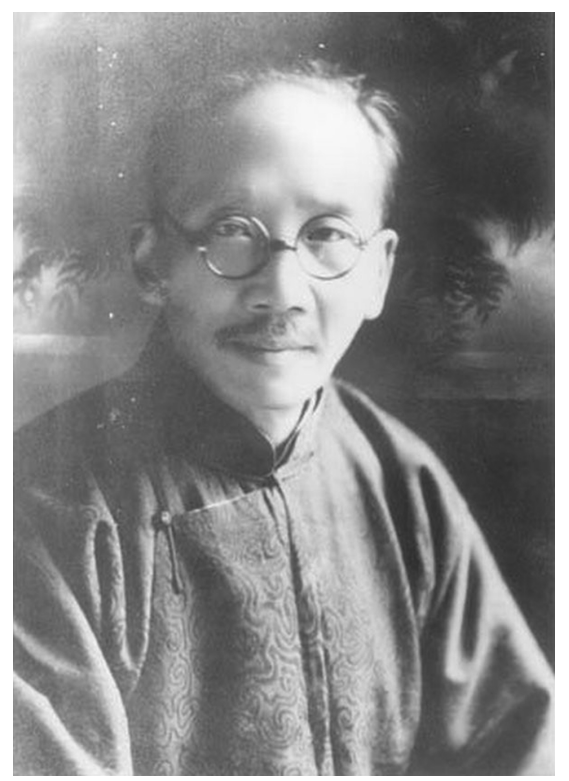

Abb. 6: Porträtbildnis von Cai Yuanpei.

Cai hatte zunächst noch das alte, auf der konfuzianischen Tradition beruhende und in die Beamtenlaufbahn einmündende Curriculum der Qing-Dynastie absolviert. 1907 ging er dann für mehrere Jahre nach Deutschland, wo er an der Universität Leipzig Philosophie studierte, insbesondere bei dem Neukantianer Wilhelm Wundt. Seit 1912 wieder in China, war Cai in der jungen Republik unter Sun Yat-sen vorübergehend als Bildungs- und Erziehungsminister tätig, woraufhin er zum Rektor der Peking Universität ernannt wurde. Nicht zuletzt unter dem Eindruck der Wissenschafts- und Bildungsbegriffe Kants und Wilhelm von Hum- 
boldts stehend und vor diesem deutschen Erfahrungshintergrund sicherlich der einflussreichste Repräsentant der chinesisch-deutschen Wechselbeziehungen dieser Epoche, verstand es Cai, das akademische Terrain zur Heimstätte des kritischen Geistes und der freien Diskussion zu machen und dies nun gerade in Unabhängigkeit von den seit 1912 immer turbulenter werdenden und schließlich - nach Yuan Shikais Tod - ins Regime der Warlords übergehenden politischen Verhältnissen Chinas.

In Cais Personal- und Berufungsentscheidungen gewann seine konsequente Verwirklichung des Ideals der Wissenschafts- und Universitätsautonomie ihren sichtbarsten Ausdruck. Das zeigt sich in exemplarischer Deutlichkeit im Blick auf die kritischen Intellektuellen, die seinerzeit bereits ein eigenständiges Profil in der chinesischen Reformdebatte und der für sie charakteristischen Überlieferungskritik gewonnen hatten und die nun von Cai an die Peking Universität berufen wurden (vgl. Chow 1967, 48-61).

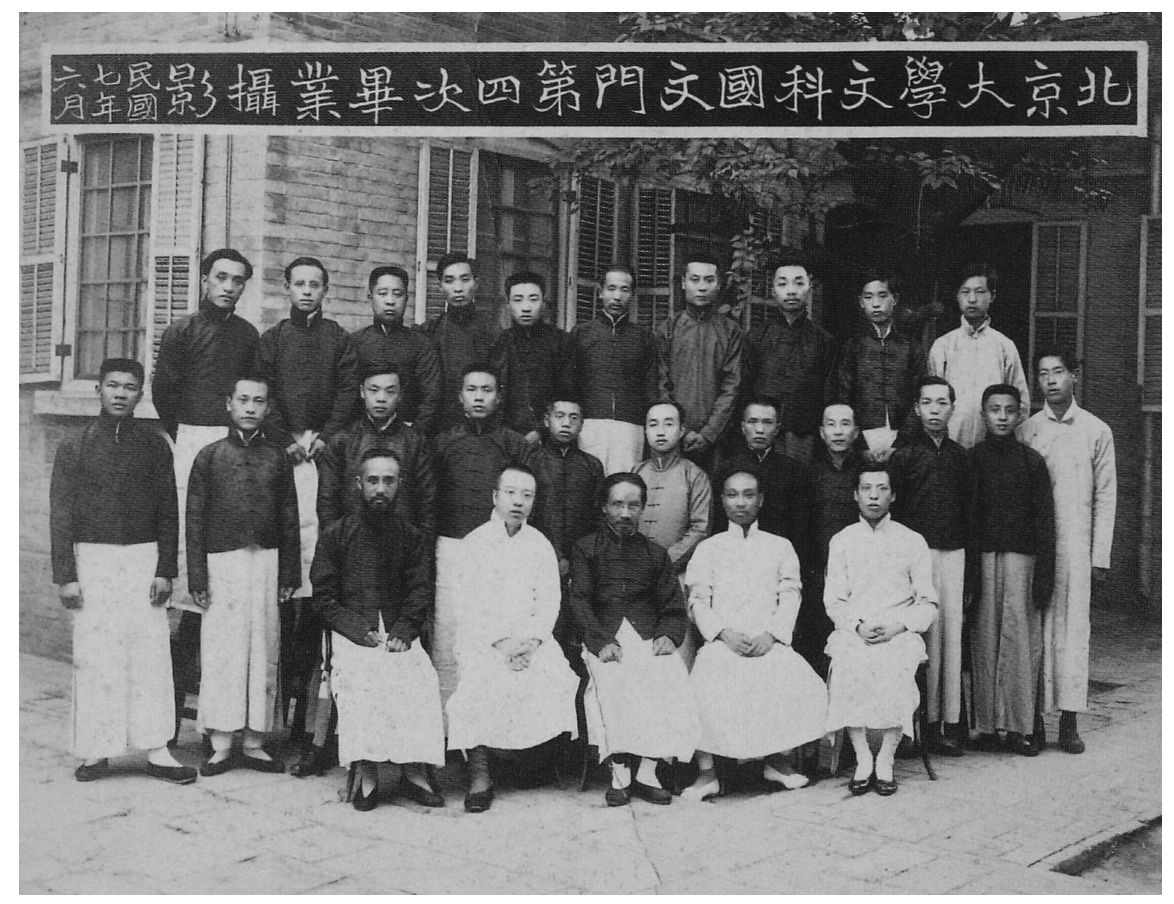

Abb. 7: Cai Yuanpei und Chen Duxiu mit Absolventen der Fakultät für chinesische Sprache. 


\section{Neue Jugend: Chen Duxiu}

An erster Stelle ist in diesem Zusammenhang Chen Duxiu (1879-1942) zu nennen, den Cai 1917 mit dem Amt des Dekans der Philosophischen Fakultät betraute. Er hatte sich während der vorhergehenden Jahre nach erfolglosen Bemühungen, das klassische, auf die traditionellen Beamtenexamina vorbereitende Literatur- und Philosophiecurriculum zu absolvieren - dessen ritualisiertes Prüfungswesen er später mit beißendem Spott überzog -, dem Studium der englischen und französischen Sprache sowie der Schiffsbautechnik in Hangzhou zugewandt und setzte dann sein Technikstudium in Japan an einer Militärhochschule fort. Wie bei so vielen seiner chinesischen Altersgenossen gehört auch in Chens Fall die Begegnung mit der rasenden Modernisierung der japanischen Gesellschaft zu den die Studienzeit prägenden Erfahrungen, die dann die spätere Überlieferungskritik dieser Generation im Rahmen der Neue-KulturBewegung im Umkreis des 4. Mai 1919 inspirieren werden.

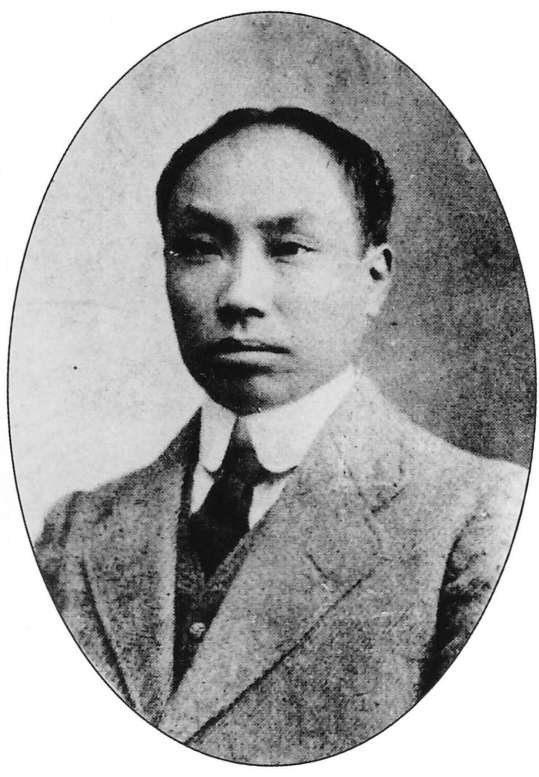

Abb. 8: Porträtbildnis von Chen Duxiu.

Nach seiner Rückkehr aus Japan hatte sich Chen solchen politischen Organisationen und revolutionären Gruppierungen angeschlossen, die den Sturz der Mandschu-Dynastie betrieben. Nachdem der jungen Republik unter Sun Yat-sen schon bald das autoritäre Regime Yuan Shikais gefolgt war, floh Chen zunächst nach 
Japan, ehe er seit 1914 von Shanghai aus durch eine vielfältige journalistische und publizistische Tätigkeit großen Einfluss auf die intellektuelle und politische Debatte in China ausübte. Eine kaum zu überschätzende Bedeutung in dem nun einsetzenden Reform- und Revolutionsprozess gewann die von Chen herausgegebene Zeitschrift Neue Jugend (Xin qingnian), die seit 1915 mit dem französischen Titel La Jeunesse und einem Jugendstilornament auf dem Heftumschlag in Shanghai erschien und rasch zum wichtigsten Organ der Neue-Kultur-Bewegung wurde (zu Deutschlandbildern in der Neuen Jugend, insbesondere zur NietzscheRezeption in den Artikeln dieser Zeitschrift, vgl. den Beitrag von Mao Mingchao im vorliegenden Band). Chen nachfolgend, zog die Redaktion der Neuen Jugend 1917 nach Peking um. Ihre prominentesten Autoren jener Jahre gehörten zugleich dem Lehrkörper der Peking Universität an. Von der ersten Ausgabe an hatte Chen die Kritik der chinesischen Überlieferung im Allgemeinen und des Konfuzianismus im Besonderen zum Hauptthema der Neuen Jugend gemacht. In allen Variationen wurde der Gegensatz zwischen Tradition und Moderne erörtert, stets standen die konfuzianischen Kardinaltugenden, die seit je her den chinesischen Alltag in der Öffentlichkeit und im Familienleben geprägt hatten, im Mittelpunkt der Diskussionen (vgl. Chow 1967, 41-48).

Die Richtung gibt Chen der neuen Jugend Chinas im September 1915 unmissverständlich gleich im Heft Nr. 1 seiner Zeitschrift vor, darin er die junge Generation zur Befolgung von sechs Grundprinzipien aufruft: „Seid unabhängig und nicht servil! - Seid fortschrittlich und nicht konservativ! - Tretet hervor und zieht euch nicht zurück! - Seid kosmopolitisch und nicht isolationistisch! - Seid wissenschaftlich und nicht phantasierend! - Seid utilitaristisch und nicht formalistisch!“ (zitiert nach Franke 1957, 38). Unüberhörbar ist Chens Ton auf die Ermutigung der individuellen Persönlichkeit gestimmt, die in den Stand gesetzt werden soll, gegen das auf Selbstdisziplinierung ausgelegte strenge Regelwerk der herkömmlichen chinesischen Erziehung zu rebellieren.

\section{6 „Leibesübungen“: Mao Zedong und Friedrich Paulsen}

In der Ausgabe der Neuen Jugend vom April 1917 erging desgleichen ein dringlicher Aufruf an die junge Generation Chinas, die Unabhängigkeit der Persönlichkeit zu kultivieren und zu diesem Zwecke, im Unterschied zu den geistigen Exerzitien der spezifisch kontemplativen philosophischen Überlieferung, die individuelle Kraft durch Körpertraining und sportliche Ertüchtigung zu steigern. Mao Zedong, seinerzeit vierundzwanzig Jahre alt und Student des Lehrerseminars der 
Provinz Hunan in Changsha, entwirft in dem Heft der Neuen Jugend unter dem Titel Eine Studie über Leibeserziehung gleichsam das Kontrastprogramm zum konservativen Bildungsideal der geistigen Übung und ihrer formalisierten Schul- und Erziehungsrituale. Anders nämlich als das mentale Training des klassischen Kanons sollte der neue Leibesunterricht „wild und hart sein. Wenn man auf einen Pferderücken springt und gleichzeitig schießt, wenn man von Kampf zu Kampf eilt; Berge durch sein Geschrei erzittern lässt und die Farben des Himmels durch ärgerliches Gebrüll verändert [. . .] dann ist alles wild und roh und hat mit Zartgefühl nichts zu tun“ (zitiert nach Spence 2001, 370).

Ein moderner, in der chinesischen Geistesgeschichte bislang unbekannter voluntaristischer Vitalismus kommt in diesen Empfehlungen zur physischen Kraftsteigerung der Persönlichkeit zu Wort. Im Hintergrund der Studie über Leibesübungen zeigt sich einerseits die zeitgenössische chinesische Rezeption Darwins und die aus seinen biologischen Prinzipien abgeleitete Theorie eines Daseinskampfes auch der Nationen und Völker, der ein entsprechendes kollektives Stärkungsprogramm erforderlich mache, um in dem nun anbrechenden Zeitalter der globalen ökonomischen, politischen und militärischen Konkurrenz bestehen zu können.

Maos Beitrag für die Neue Jugend ist dann aber andererseits offensichtlich auch inspiriert durch seine intensive Lektüre des Systems der Ethik von Friedrich Paulsen. Sie zählt zu den geistigen Schlüsselerlebnissen in Maos Studienjahren, die er dem von ihm verehrten Ethik- und Soziologiedozenten an der Lehrerbildungsanstalt, Yang Changji (1871-1920), zu verdanken hatte. Zwischen 1902 und 1913 hatte Yang Changji Erfahrungen im westlichen Schul- und Hochschulwesen bei Studienaufenthalten in Deutschland, England und Japan gesammelt. Über Yangs Vermittlung fand Paulsens Werk dann Eingang in die Lehrerausbildung in der Provinz Hunan - sicherlich zunächst nur ein Detail der chinesisch-deutschen Wechselbeziehungen im Umkreis der Neue-Kultur-Bewegung, aber doch wohl eines von exemplarischer Bedeutung und nachhaltiger Wirkung (vgl. Spence 2003, 43-53; Schmidt-Glintzer 2017, 40-47).

Friedrich Paulsen (1846-1908), Ordinarius für Philosophie und Pädagogik an der Berliner Friedrich-Wilhelms-Universität, gehörte im deutschen Kaiserreich zu den wirkmächtigsten Professoren, dessen Werke, in hoher Auflage gedruckt und in zahlreiche Sprachen übersetzt, ein großes nationales und internationales Publikum erreichten. Sein System der Ethik erschien 1909 in der chinesischen Übersetzung von Cai Yuanpei, zuvor war es bereits ins Japanische übersetzt worden. Relevanz für die Reformfraktion in China gewann Paulsen vor allem auch durch seine bildungspolitischen Modernisierungskonzepte. Maßgeblich war er beteiligt an der Etablierung des Realgymnasiums und seines neuphilologischen und naturwissenschaftlich-technischen Curriculums, das im preußischen Schulsystem 
gleichberechtigt an die Seite des herkömmlichen altsprachlich-humanistischen Gymnasiums trat (vgl. Steensen 2010, 20-23, 108-114).

In diesem Zusammenhang steht Paulsens Forderung, den für die Abiturprüfung ehedem obligatorischen Lateinaufsatz durch den „deutschen Aufsatz“ zu ersetzen - trotz aller großen kulturellen und historischen Differenzen zwischen Deutschland und China ein mit den Modernisierungsbestrebungen in der chinesischen Bildungs-, Sprach-, Schul- und Prüfungsdebatte durchaus vergleichbares Phänomen, zählte doch die Sprach-, Schrift- und Literaturreform und die entsprechende Modernisierung des Schul-, Prüfungs- und Hochschulwesens zu den Hauptanliegen der Neue-Kultur-Bewegung. Der im geistesgeschichtlichen und symbolischen Verständnis bedeutungsschwerste Gegenstand, auf den die Kritik der Reformer zielte, war der in der klassischen Schriftsprache verfasste konfuzianische Kanon, der jahrhundertelang den Unterricht dominierte und der im Mittelpunkt der strikt auf das chinesische Altertum ausgerichteten traditionellen Prüfungen stand (vgl. Höllmann 2015, 14-20).

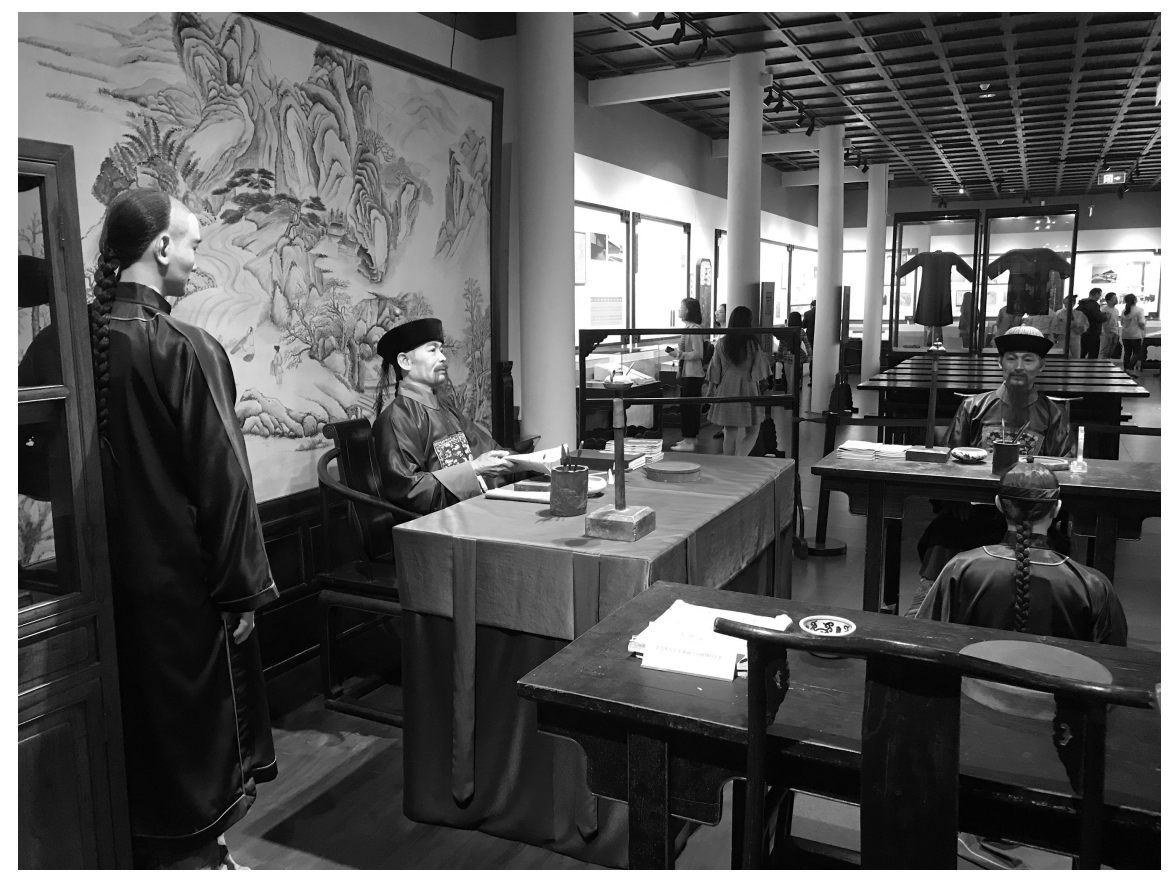

Abb. 9: Konfuzius-Akademie Peking: Modell der traditionellen Unterrichtssituation.

Aufschlussreich im Blick auf die philosophisch-pädagogischen Diskussionen in China sind auch die ausführlichen Kommentare, in denen Mao seine Paulsen-Lek- 
türe dokumentiert hat. „Willensfreiheit“ und „Willenskraft“ lauten die Schlüsselworte dieser Reflexionen über das System der Ethik. Dazu notiert Mao:

Der wahrhaft große Mensch entfaltet seine natürlichen Anlagen [. . .]. Die Taten des Helden sind seine eigenen Taten, sind Ausdruck seiner Willenskraft, erhaben und reinigend, und berufen sich auf kein Vorbild. Seine Kraft gleicht einem sturmmächtigen Wind [. . .], eine Macht, die grenzenlos ist und der man keinen Einhalt gebieten kann. Vor ihr weichen alle Hindernisse. (Zitiert nach Schmidt-Glintzer 2017, 45; vgl. Chang und Halliday 2007, 29-32)

\section{Chen Duxius Umwertung der konfuzianischen Werte}

Die systematische Argumentation für die Befreiung der individuellen Persönlichkeit von den allgewaltigen Vorbildern der Tradition und von den durch dieselben repräsentierten herkömmlichen Bildungs- und Erziehungsidealen entwirft Chen Duxiu seit 1915 in seinen Beiträgen für die Neue Jugend. Das Stichwort, mit dem sein „Aufruf an die Jugend“ einsetzt, lautet denn auch Emanzipation. Mit Bezug auf die neuere europäische Geschichte, die als Prozess der politischen Revolutionen, der Säkularisierung sowie der zunehmenden Gleichberechtigung und mithin als eine „Geschichte der Emanzipation“ zu lesen sei, appelliert Chen an die junge chinesische Generation, sich aus der in Familie und Schule eingeübten Fixierung auf die Vergangenheit zu lösen und endlich in die modernen Verhältnisse der kosmopolitischen Welt des 20. Jahrhunderts aufzubrechen:

Emanzipation bedeutet Selbstbefreiung aus den Fesseln der Knechtschaft und Vollendung der vollkommen unabhängigen und freien Persönlichkeit. [. . .] Sobald einmal die unabhängige Persönlichkeit anerkannt ist, sollten alle Angelegenheiten des Benehmens, alle Rechte und Privilegien und jegliche Überzeugung der natürlichen Fähigkeit jeder Person überlassen werden. Es gibt definitiv keinen Grund dafür, warum man blindlings anderen folgen sollte. Wie denn auch Loyalität, kindliche Ergebenheit, Keuschheit und Rechtschaffenheit Ausdruck einer sklavischen Gesinnung sind [. . .].

(Zitiert nach Lawrance 2004, 2)

Offenkundig zielen die polemischen Passagen von Chens Appell auf die Kardinaltugenden des Konfuzianismus und auf die mit ihnen verbundene traditionelle chinesische Familien- und Gesellschaftsordnung, in der im Sinne einer strikt patriarchalischen Hierarchie das Verhältnis von Herrscher und Untertanen, Vater und Sohn, Ehemann und Ehefrau, Älteren und Jüngeren, Ahnen und nachfolgenden Generationen festgelegt ist (vgl. Gu 1999, 37-47). Die tragenden Fundamente dieser aus der Lehre einer universellen Harmonie abgeleiteten, in formalisierten Verhaltens-, Anstands- und Sittlichkeitsnormen penibel 
geregelten Herrschafts-, Familien-, Geschlechter- und Generationsverhältnisse bringt Chen ins Wanken, wenn er Loyalität, Pietät, Ehrerbietung, Keuschheit und Rechtschaffenheit als typische Kennzeichen einer lebensfeindlichen Sklavenmoral bloßstellt.

Deutlich sichtbar tritt in den an die junge Generation Chinas gerichteten Manifesten Chens deren Inspiration durch die Nietzsche-Lektüre in den Blick. Wie überhaupt Nietzsches Philosophie der „Umwertung der Werte“ und die einschlägigen Begriffe der „Herren-“ und „Sklavenmoral“ sowie der Willensfreiheit auf dem Wege der zeitgenössischen japanischen und chinesischen NietzscheÜbersetzungen eingehen in die ikonoklastische Programmatik der Neue-KulturBewegung. Die Rezeption von Nietzsches Lebens- und Willensphilosophie kann sich dann wiederum mit den vitalistischen Konzepten eines zeittypisch politisch aufgeladenen Sozialdarwinismus verbinden. In diesem Fall wird die Befreiung von dem die Willens- und Lebenskräfte schwächenden Ballast der Tradition und der Geschichte zur Voraussetzung dafür, den modernen Kampf ums Dasein der Völker und Nationen bestehen zu können. Da in Chens Augen seit Beginn des Ersten Weltkriegs die Epoche dieser nunmehr globalen Auseinandersetzung angebrochen ist, hält er lakonisch fest: „Mir wäre das Verschwinden der alten Kultur unserer Nation viel lieber als mitansehen zu müssen, wie unser Volk nun ausstirbt aufgrund seiner Lebensuntauglichkeit in der modernen Welt“ (zitiert nach Lawrance 2004, 2).

Die weltfremden Traditionalisten, die immer noch den isolationistischen und kontemplativen Idealen des alten China anhingen - der Vorliebe für das „ruhige Eremitenleben“ und für die „Eremitenliteratur“ -, glaubten, so konstatiert Chen fassungslos, sich dem modernen Epochenwechsel entziehen zu können. Unmöglich sei es jedoch, dem „Kampf ums Dasein“ auszuweichen, er reiße alle ins dynamische Weltgeschehen hinein. Der Rückzug aus der Welt, einstmals die souveräne Geste der Meister der Meditation (der „Eremiten“), sei heute kein Ausweis mehr von Weisheit und Geisteskraft, sondern nur noch ein Zeichen verächtlicher Schwäche. Dem Argumentationsmodell der „Umwertung der Werte“ genau folgend, stellt Chen daher fest: „Um es in freundlichen Worten zu sagen: Der Rückzug [in die Kontemplation] ist die Handlungsweise, in der der überlegene Mensch Abstand von der vulgären Welt gewinnt. Um es in unfreundlichen Worten zu sagen: Es ist das Kennzeichen der Schwachen, die unfähig sind, den Kampf ums Überleben zu führen“ (zitiert nach Lawrance 2004, 3). 


\section{Historische Dialektik: Chen Duxius Weg in den Marxismus}

Längst sei für die junge Generation die Zeit gekommen, in der Auseinandersetzung mit den Eltern und Lehrern sowie mit der Überlieferung insgesamt die unfreundlichen Worte zu wählen. Unausweichlich nämlich stehe China jetzt vor der entscheidenden Alternative zwischen Kontemplation und Aktion, Vergangenheit und Zukunft, Tradition und Moderne - und zuletzt Tod und Leben: „Wenn eine Nation in den Strom der Weltereignisse geworfen wird, werden Traditionalisten den Tag des Zusammenbruchs dieser Nation zügig herbeiführen, aber jene, die zum Wandel befähigt sind, werden die Gelegenheit ergreifen, um zu kämpfen und vorwärts zu streben“ (zitiert nach Lawrance 2004, 3), weshalb es eine Überlebensfrage und ein Gebot der Vernunft ist, sich von der die Kräfte schwächenden Überlieferung und von den sich an sie klammernden Traditionalisten loszusagen. Und dann fügt Chen gar noch eine dialektische Deutung der Kolonialgeschichte in China hinzu:

Geht es nach den Pessimisten, so hat unser Land seit der [durch die „Ungleichen Verträge“ erzwungenen] Öffnung der Handelshäfen Territorium verloren und Entschädigungen bis zur Erschöpfung gezahlt. Hält man sich jedoch an die Optimisten, so würden wir ohne die Segnungen [sic!] des chinesisch-japanischen Krieges von 1895 und ohne den Boxer-Aufstand von 1900 immer noch im Zeitalter des „achtbeinigen Essays“ [eine der besonders berüchtigten Aufgaben im traditionellen Prüfungssystem] und des Zopfes leben.

(Zitiert nach Lawrance, 3)

In seiner provokativen Umwertung der etablierten historischen Deutungsmuster feiert Chen die List der Weltgeschichte, die - nun ausgerechnet in den demütigenden Auseinandersetzungen Chinas mit den Kolonialmächten - der neuen Jugend das größte Hindernis auf dem Weg in die Zukunft aus dem Weg geräumt hat: den Irrglauben des alten Kaiserreichs, man könne den Herausforderungen der Moderne mit einer „isolationistischen Politik der geschlossenen Türen“ (zitiert nach Lawrance 2004, 3) begegnen. Die durch eine anachronistische Kultur verriegelten Tore Chinas, so die von Chen enthüllte Ironie der Geschichte, mussten erst von außen gewaltsam aufgesprengt werden, um das Land für eine Entwicklung im Sinne von Fortschritt und Emanzipation zu öffnen.

Es liegt nahe, in Chens dialektisch-hegelianischer Deutung der demütigenden Kolonialgeschichte eine Reminiszenz der berühmten China-Passagen im Manifest der Kommunistischen Partei zu erkennen, die den Autoren als Illustration ihrer Hauptthese, des Zusammenhangs von ökonomischer Modernisierung und politischer Revolution, dienen: „Der ostindische und chinesische 
Markt [. . .] gaben dem Handel, der Schiffahrt, der Industrie einen nie gekannten Aufschwung und damit dem revolutionären Element der zerfallenden feudalen Gesellschaft eine rasche Entwicklung“ (Marx und Engels 1959, 463). Dieser Befund gilt in zweifacher Richtung: Sowohl in der alten Welt der Kolonialmächte befördert die moderne Ökonomie den Zerfall der überkommenen feudalen Gesellschaftsstrukturen wie auch in den kolonisierten bzw. in den wie China - zum Welthandel gezwungenen Ländern der Neuen Welt und des Fernen Ostens.

Unter Bezugnahme auf die Opiumkriege und die „Ungleichen Verträge“ stellen Marx und Engels dann über die Unaufhaltsamkeit des von der industriellen Produktion entfachten globalen Modernisierungsprozesses fest:

Die Bourgeoisie reißt durch die rasche Verbesserung aller Produktionsinstrumente, durch die unendlich erleichterte Kommunikation alle, auch die barbarischsten Länder in die Zivilisation. Die wohlfeilen Preise ihrer Waren sind die schwere Artillerie, mit der sie alle chinesischen Mauern in den Grund schießt [. . .]. Sie zwingt alle Nationen, die Produktionsweise der Bourgeoisie sich anzueignen, wenn sie nicht zugrunde gehen wollen; sie zwingt sie, die sogenannte Zivilisation bei sich selbst einzuführen.

(Marx und Engels 1959, 466)

Im Zuge dieses veritablen Globalisierungsprozesses werden ,alle feudalen, patriarchalischen, idyllischen Verhältnisse zerstört“ (Marx und Engels 1959, 466), wie sich schließlich in einer universellen Dynamik die in überlieferten nationalen und regionalen Kulturen verfestigten Strukturen sämtlich auflösen werden: „Alles Ständische und Stehende verdampft. Alles Heilige wird entweiht, und die Menschen sind endlich gezwungen, ihre Lebensstellung, ihre gegenseitigen Beziehungen mit nüchternen Augen anzusehen“ (Marx und Engels 1959, 465).

Die Übertragbarkeit des von Marx und Engels aus den europäischen Verhältnissen abgeleiteten Modells auf jene chinesische Szenerie, wie sie sich dem Betrachter nach dem Zusammenbruch des Kaiserreichs und angesichts der wirtschaftlichen Aktivitäten der Kolonialmächte zeigt, liegt auf der Hand. Chen Duxiu hat sich in den folgenden Jahren dann auch nicht mehr auf historische und theoretische Analysen beschränkt, sondern hat sich der politischen Praxis zugewandt und jenen marxtypischen Gedankengang beim Wort genommen, demnach es darauf ankomme, sich an die Spitze der Geschichtsbewegung zu stellen, das Heft des Handelns selbst in die Hand zu nehmen und den ohnehin unvermeidlichen Modernisierungsprozess nicht von außen zu erleiden, sondern in China zu befördern, um solchermaßen der Emanzipation und zuletzt der Revolution das Terrain zu bereiten. Chen gehörte denn auch zu den Gründungsmitgliedern der Kommunistischen Partei Chinas, zu deren erstem Generalsekretär er 1921 in Shanghai gewählt wurde. 


\section{9 „Mr Democracy and Mr Science“}

Vorerst jedoch, als Dekan an der Peking Universität und im Umkreis des 4. Mai 1919, galt Chens Engagement der Neue-Kultur-Bewegung, der er freilich auch im akademischen Bereich eine dezidiert politische Ausrichtung zu geben versuchte. In einem seiner berühmtesten Artikel in der Neuen Jugend verteidigt er im Januar 1919 die traditionskritischen Autoren dieser Zeitschrift, die sich für die „beiden Herren ,Democracy“ und ,Science““ eingesetzt hatten. Abermals zielt Chen dabei auf den konfuzianischen Tugendkanon:

Um sich für jenen Herrn ,Democracy“ einzusetzen, können sie nicht umhin, sich gegen den Konfuzianismus, gegen die Gesetze der Sitte, gegen die Keuschheit, gegen die althergebrachte Ethik und gegen die althergebrachte Politik zu wenden; und um sich für jenen Herrn ,Science‘ einzusetzen, können sie nicht umhin, sich gegen die althergebrachten Künste und gegen die althergebrachte Religion zu wenden; und um sich für die beiden Herren ,Democracy‘ und ,Science‘ einzusetzen, können sie nicht umhin, sich gegen das nationale Erbgut und gegen die althergebrachte chinesische Literatur zu wenden.

(Zitiert nach Franke 1957, 49)

Es gibt in Chens Perspektive keinen Kompromiss zwischen chinesischer Tradition und Moderne. Den von Chen auf ganzer Front ausgerufenen Kampf gegen die Überlieferung - gegen alte Ethik, alte Sittengesetze, alte Politik, alte Kunst, alte Religion - führen die seinerzeit an dieser Hochschule wirkenden Reformkräfte in exemplarischer Konsequenz auf dem Feld der Sprache und Literatur (vgl. Chow 1967, 269-279).

War die staatstragende konfuzianische Überlieferung bereits 1905 mit der Abschaffung des herkömmlichen, die Kenntnis des alten Literaturkanons voraussetzenden Prüfungssystems in die Defensive geraten, so haben sich die Aktivisten der Neue-Kultur-Bewegung einen prinzipiellen Traditionsbruch in der allgemeinen Sprach- und Alltagskultur sowie die Kritik der gesamten alten Gelehrsamkeitsüberlieferung auf die Fahnen geschrieben. Eine neue, standardisierte Volkssprache in einer vereinfachten Schrift soll etabliert werden. Zur neuen Kultur soll vor allem eine moderne realistische Literatur beitragen, diesseits der literarischen Klassik, ihres strengen Stils sowie ihrer traditionellen Formen und Inhalte. In solchen stets auf die nationale Einheit Chinas bezogenen sprach- und literaturpolitischen Forderungen stimmen die prominenten Repräsentanten der Bewegung überein, auch wenn sich später auf dem politischen Terrain ihre Wege wieder trennen (vgl. Schmidt-Glintzer 1999, 497-505). 


\section{Neue Literatur: Realismus}

Das Leitwort, unter das die Reformer an der Peking Universität und im Umkreis der Zeitschrift Neue Jugend ihre sprach- und literaturpolitischen Aktivitäten stellen, lautet Realismus. Wirkmächtigster Stichwortgeber in der weite Kreise ziehenden chinesischen Realismusdiskussion war der Philosoph und Philologe Hu Shi (1891-1962). Auch sein Lebensweg folgt der für viele Angehörige der Reformfraktion typischen Bahn. Hus Bildungsgeschichte nahm ihren Anfang beim klassischen Literaturstudium des alten Schulsystems, ehe er an eine nach japanischem Vorbild modernisierte Schule in Shanghai wechselt und dann mit einem Auslandsstipendium zum Philosophiestudium in die Vereinigten Staaten aufbricht, wo er an der Columbia Universität in New York bei dem Philosophen und Reformpädagogen John Dewey seine Doktorarbeit schreibt. Deweys philosophischer Pragmatismus sollte stets prägend für Hus Positionen in der NeueKultur-Bewegung bleiben. Eine ihrer populärsten Losungen - ,zerschlagt den Konfuzius-Laden!“ - geht zwar auf Hu Shi zurück (van Ess 2009, 104). Indessen zählte er später keineswegs zu den Vertretern des kompromisslosen Ikonoklasmus, die den radikalen Bruch mit der Überlieferung einforderten. Hu versuchte vielmehr, durch penibles Quellenstudium auch in der Geschichte des chinesischen Schrifttums Anknüpfungspunkte für eine neue, realistische Ästhetik zu finden, diesseits des streng formalistischen Stils der konfuzianisch geprägten Klassik (zu Hu Shis Position in der Neue-Kultur-Bewegung und im Umkreis des 4. Mai 19919 vgl. den Beitrag von Qin Mingrui im vorliegenden Band).

$\mathrm{Hu}$ Shi gehörte desgleichen $\mathrm{zu}$ jenen traditionskritischen Intellektuellen, die von Cai Yuanpei an die Peking Universität berufen wurden. Seit 1917 lehrte er dort als Philosophieprofessor, wo er eng mit Chen Duxiu zusammenarbeitete, dessen späteren Weg in den Marxismus er freilich als überzeugter Verfechter des Pragmatismus kritisierte (zur chinesischen Deutung des 4. Mai 1919 und zur entsprechenden Debatte zwischen den Positionen der marxistischen Revolution und der aufklärerischen Reform vgl. den Beitrag von Fang Bo im vorliegenden Band). Zunächst jedoch gehörte er zum Autorenkreis der Neuen Jugend und entfaltete in seinen Beiträgen zu dieser Zeitschrift das Programm für eine Sprach-, Schrift- und Literaturreform im Geiste des Realismus. Dazu zählen auch seine „Vorschläge für eine literarische Reform“, die im Januar 1917 in der Neuen Jugend erschienen und Hus berühmte, auf die herkömmlichen literarischen Konventionen - auf Formalismen, klassische Stil- und Zitierregeln sowie auf die höchst subtilen Anspielungskünste - polemisch gemünzte „acht Leitsätze“ enthielten, darunter die Forderungen: „Den Worten muss ein konkreter Gehalt zugrunde liegen. Ahme nicht den Stil und die Ausdrucksweise der Alten nach! [.. .] Mache dich frei von veralteten Phrasen oder Redewendungen! Verwende 

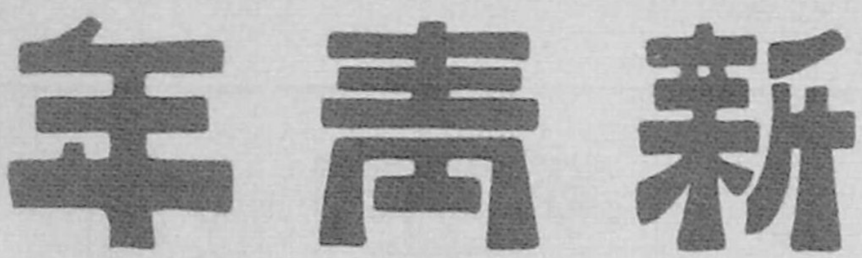

瀷主生先秀 獨 陳

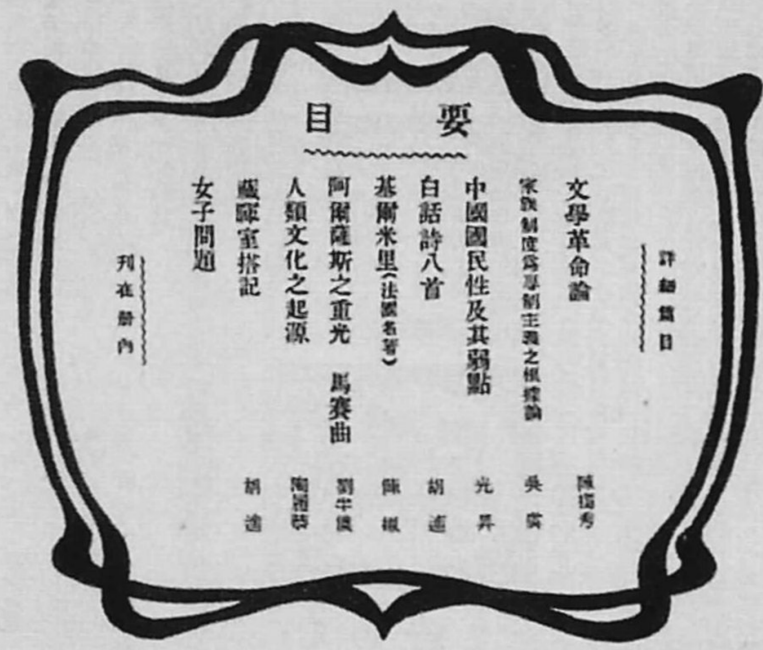

就赫年清名原

號六第管二第

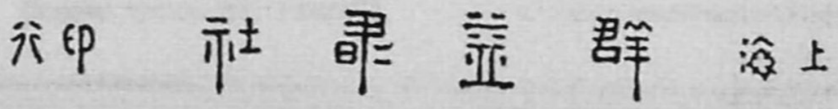

Abb. 10: Die Ausgabe der Neuen Jugend von 1917, in der Hu Shis „Thesen zur Literaturreform“ veröffentlicht wurden. 


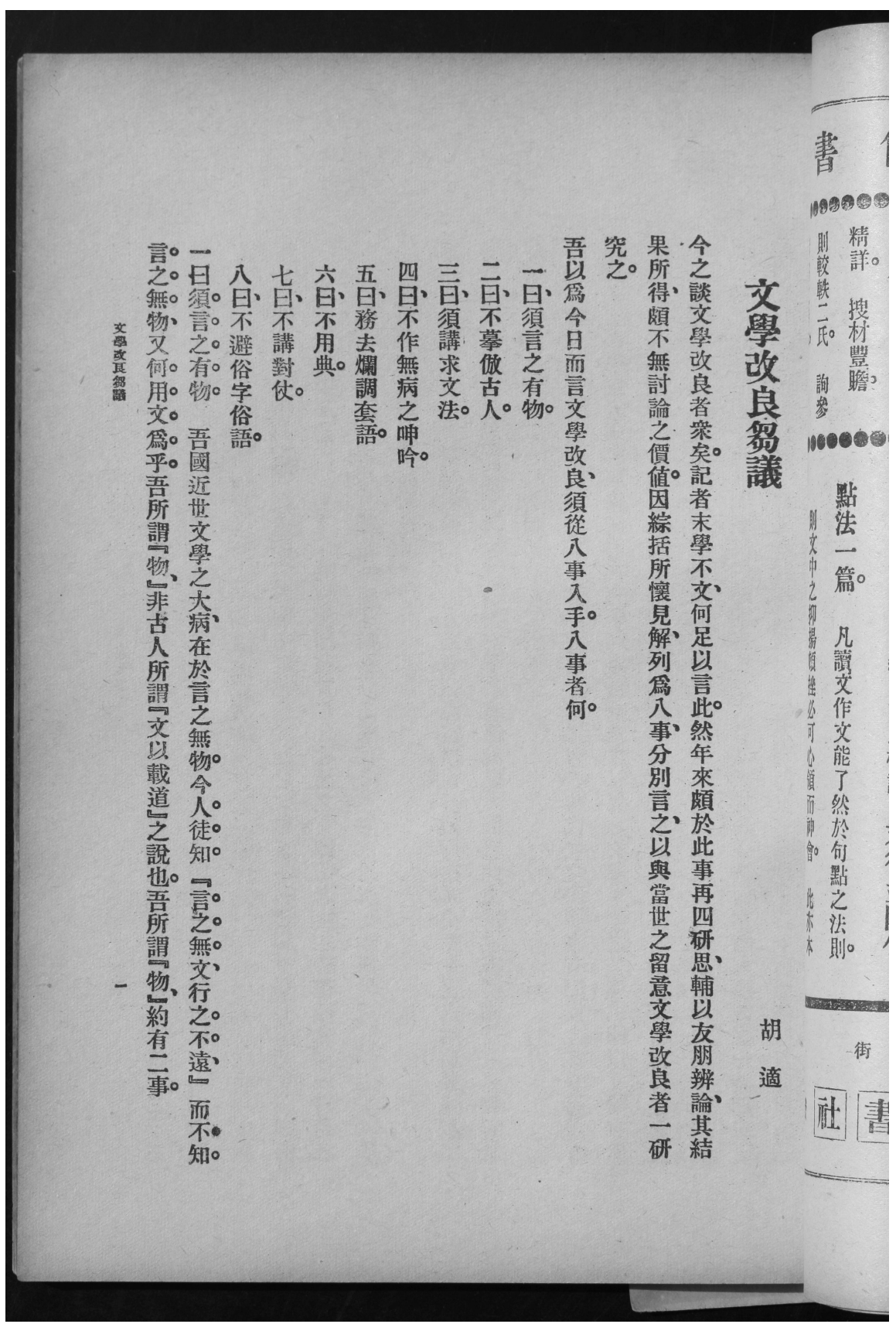

Abb. 11: Die acht Thesen zur Literaturreform. 
keine Zitate! Vermeide allen stilistischen und gedanklichen Parallelismus! Habe keine Scheu vor Wörtern und Redewendungen der volkstümlichen Sprache“ (zitiert nach Franke 1957, 55; Chow 1967, 273-275).

In der folgenden Februarausgabe der Neuen Jugend greift Chen Duxiu das Programm Hus auf, um es dann freilich unter dem Titel „Über die literarische Revolution“ im Sinne eines radikalen Ikonoklasmus zuzuspitzen. Kulturrevolution und politische Revolution rücken in Chens Diktion schon hörbar zusammen, wenn er sich gegen die Gelehrsamkeitsüberlieferung des alten Schul- und Bildungssystems und gegen dessen ästhetische und literarische Ideale wendet:

Ich will der Feindschaft der Schulmeister des ganzen Landes trotzen und hoch das Banner der „Armee der literarischen Revolution“ hissen zur Unterstützung meines Freundes [d. i. Hu Shi]. Auf dem Banner sind mit großen Lettern die drei großen Prinzipien unserer revolutionären Armee geschrieben: 1 . Nieder mit der gekünstelten, unwahren, aristokratischen Literatur! Schafft eine natürlich-einfache, lyrische Volksliteratur! 2. Nieder mit der vermoderten, nicht realistischen Zitaten-Literatur! Schafft eine neue, wahrheitsgetreue, realistische Literatur! 3. Nieder mit der unklaren, schwierigen, lebensfernen Berg- und Waldliteratur! Schafft eine klare, allgemeinverständliche, soziale Literatur!

(Zitiert nach Franke 1957, 56-57)

Sicherlich nicht als exakte Konsequenz aus dieser literaturpolitischen Agitation, aber eben doch als radikaler Bruch mit der literarischen Überlieferung ist Das Tagebuch eines Verrückten, eine Erzählung des Schriftstellers Lu Xun (1881-1936), zu verstehen, die 1918 in der Neuen Jugend erscheint und gemeinhin als jener Schlüsseltext angesehen wird, mit dem die Moderne in der Literatur Chinas einsetzt. Auch Lus Schulbildung begann noch im alten, konfuzianisch geprägten Erziehungssystem, das er aber noch vor den Prüfungen verließ, die für die Beamtenlaufbahn im Kaiserreich qualifizierten. Nachdem er ein Studium zunächst an einer Marineakademie, dann an einer Hochschule für Bergbau und Eisenbahnbau aufgenommen hatte - an solchen technischen Hochschulen also, die seinerzeit von der Qing-Regierung im Rahmen der chinesischen Selbststärkungsbewegung nach westlichem Vorbild gegründet worden waren -, wechselte Lu zum Medizinstudium nach Japan, das er aber bald abbrach, um sich Sprach- und Übersetzungsstudien sowie der europäischen und amerikanischen Literatur- und Philosophiegeschichte zu widmen. Nicht zuletzt die Nietzsche-Lektüre zählte zu Lus prägenden intellektuellen Erfahrungen dieser Zeit.

Zurückgekehrt nach China, arbeitete Lu zunächst als Lehrer. Nach Gründung der Republik erhielt er 1912 an dem von Cai Yuanpei geleiteten Erziehungsministerium eine Anstellung in Peking, wo er später dann auch an der Peking Universität als Dozent für Literaturgeschichte unterrichtete (zu Lu Xuns Studien zur chinesischen Literatur vgl. im vorliegenden Band den Beitrag von Wang Liping) und schon bald zu den Autoren zählte, dessen Texte regelmäßig in der Neuen Jugend veröffentlicht wurden. Seine im Mai 1918 in dieser Zeitschrift publizierte, sogleich beim Pu- 


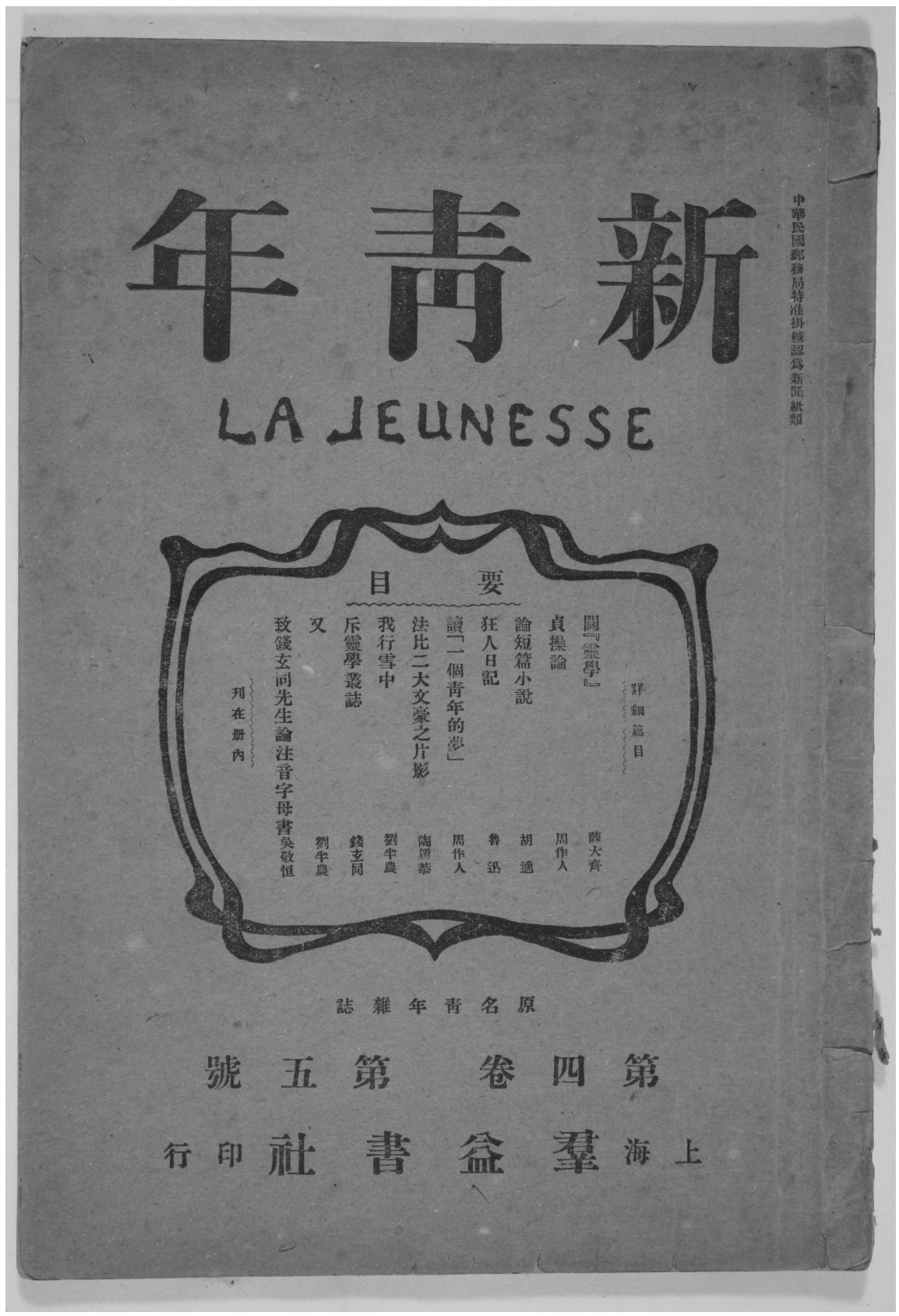

Abb. 12: Das Titelblatt der Ausgabe der Neuen Jugend mit Lu Xuns „Tagebuch eines Verrückten“. 
blikum Furore machende, in chinesischer Umgangssprache verfasste Kurzgeschichte Das Tagebuch eines Verrückten wird man - über die subtil gebrochene Komposition der Erzählung hinweg - als seinerzeit drastischste Abrechnung mit der klassischen chinesischen Überlieferung, mit ihren Konventionen und ihrer hochartifiziellen Sprache ansehen. Das geschieht in der radikal subjektivistischen Perspektive eines vermeintlich „Verrückten“. Verrückt ist dieser Diarist freilich nur in den Augen der alten Welt, deren Irrsinn nun gerade in seinen Aufzeichnungen aufgedeckt wird.

Beim nächtlichen Studium der Geschichtsquellen macht er eine Entdeckung, die den herkömmlichen Tugendkanon in seiner wahren Bedeutung ins Gegenteil verkehrt: „Ich bin daher die Geschichtsbücher durchgegangen; sie waren ohne Jahresangaben, und auf jeder Seite standen krumm und schief die Worte ,Humanität, Rechtlichkeit, Wahrheit und Tugend' gekritzelt. Da ich ohnehin nicht schlafen konnte, las ich aufmerksam die halbe Nacht, bis ich zwischen den Zeilen die zwei Worte erkannte, aus denen jedes Buch bestand: ,Menschen fressen“!“ (Lu Xun 2015, 20). Die Erkenntnis, dass die gesamte jahrtausendealte Überlieferung

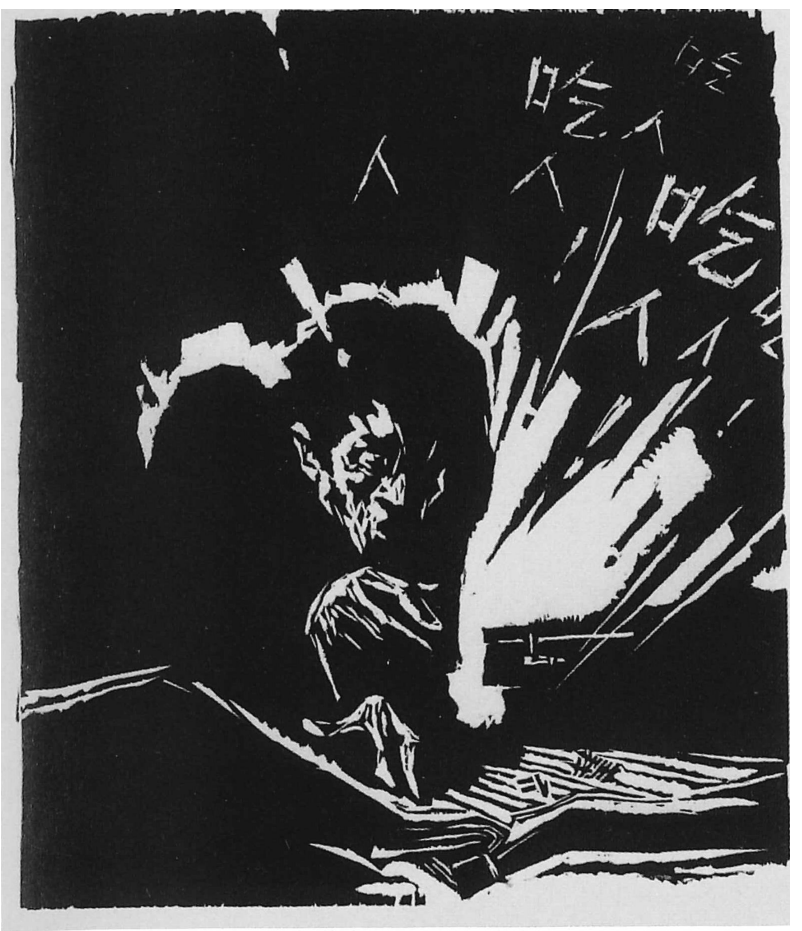

Abb. 13: Illustration zum „Tagebuch eines Verrückten“, die Lu Xuns Vorliebe für expressionistische Graphik zeigt. 
Chinas auf diese beiden Worte zusammenschrumpft, weitet sich schließlich bei dem Autor des Tagebuchs zu einer schauerlichen Ahnung aus:

Seit viertausend Jahren sind Menschen gefressen worden, und ich habe wie ein Narr so viele Jahre meines Lebens vertan. Als meine Schwester starb, war mein Bruder mit den Familienangelegenheiten betraut. Es ist nicht auszuschließen, dass er ihr Fleisch in die Speisen mischte und uns heimlich davon zu essen gab. Vielleicht habe ich selbst, ohne es zu merken, ein paar Stücke Fleisch von meiner Schwester gegessen, und nun ist die Reihe auch an mir . . . Viertausend Jahre Menschenfresserei lasten auf mir.

(Lu Xun 2015, 31)

In der Umkehrung der herkömmlichen Perspektive durch den vermeintlich Verrückten - es handelt sich um eine veritable Umwertung der Werte - nehmen sich die chinesische Geschichte und die in ihr dominierenden Ideale des Konfuzianismus gar nicht als kulturelle Überlieferung aus, sondern als Kannibalismus kulturloser Barbaren. Menschenfressend, so der dem Konfuzianismus entgegengeschleuderte Vorwurf, ist die Tradition, weil sie den Lebendigen ihre eigene Individualität und Subjektivität raubt, ihnen den Weg zur Wirklichkeit versperrt. Die Riten des konfuzianischen Ahnenkultes, das verknöcherte Patriarchat, die allgegenwärtigen Angelegenheiten der Familie und der arrangierten Ehen, Ausgangskonstellation der konfuzianischen Gesellschaftsordnung, ketten die Lebenden an die Vergangenheit und binden sie ein in die strenge Hierarchie von Jung und Alt, Kindern und Eltern, Frauen und Männern, Untertan und Herrscher. Der penible Kult der Vergangenheit zu Lasten von Gegenwart und Zukunft frisst das Leben der individuellen Persönlichkeit auf, so der rebellische, unüberhörbar auch durch die Schule Nietzsches gegangene Subjektivismus Lu Xuns.

\section{Sturm und Drang: Werther und Prometheus}

Auf dem gleichen Wege wie Lu Xun, über das Medizinstudium in Japan und über die damit verbundenen Sprachstudien, war desgleichen Guo Moruo (1892-1978) - neben Lu der wohl wirkmächtigste Autor jener aus der NeueKultur-Bewegung hervorgehenden chinesischen Moderne - der europäischen Literatur begegnet, die auch in seinem Fall die Rebellion des selbstbewussten Subjekts gegen eine entindividualisierende Tradition beflügelte. In den Schriften Guo Moruos geht die Befreiung des Individuums einher mit der Feier einer aus dem subjektiven Erleben hervorgehenden Kunstproduktion. Als literarisches Vorbild hat sich Guo Moruo den jungen Goethe, den Repräsentanten der Sturm-undDrang-Epoche und ihrer Genieästhetik, auserkoren, dessen Werke er bei seinen Literaturstudien und Übersetzungsübungen in Japan kennengelernt hatte. Werther, 
Faust und Prometheus sind bezeichnenderweise Guos Identifikationsfiguren in Goethes Werk, das er der jungen Generation in Übersetzungen zugänglich machen wird, um solchermaßen nun auch einer chinesischen Sturm-und-Drang-Bewegung den Weg zu bereiten (Chow 1967, 285-287; zu Guo Moruo als Übersetzer und Vermittler deutscher Literatur vgl. den Beitrag von Han Jie im vorliegenden Band). Im Zeichen der emotionalen und intellektuellen Selbstbestimmung steht seine 1921 erscheinende Gedichtsammlung Göttinnen, in der Guo, wie zuvor Lu Xun auf dem Felde der erzählenden Literatur, in der Lyrik den Bruch mit der literarischen Überlieferung und die Wende zur Ästhetik der Moderne vollzieht. „Wie ich“ lautet in Goethes Prometheus-Hymne der letzte Vers des heroisch-selbstgewissen Protests gegen die alte Welt. Die ganze Welt soll „wie ich“ werden und sich dem schöpferischen Willen des autonomen Individuums fügen. Im Stile dieses rebellischen Prometheismus setzen denn auch achtundzwanzig Verse von Guos Gedicht „Himmelshund“ mit „Ich“ ein und münden in der letzten Zeile in den voluntaristischen Ausruf „Mein Ich will bersten!“ (vgl. Kubin 1985, 35-36; Schmidt-Glintzer 1999, 513-516).

1922 erscheint Guo Moruos Werther-Übersetzung in der von der 4.-MaiBewegung geforderten allgemein verständlichen Umgangssprache. Sie löst eine veritable Werther-Begeisterung, gar ein chinesisches Werther-Fieber aus (Wuneng 2000, 37-41, Schmidt-Glintzer 1999, 500). Die Leiden des jungen Werthers scheinen in Guo Moruos Übersetzung nahtlos anzuschließen an Lu Xuns Tagebuch eines Verrückten und dessen Literaturrevolution fortzusetzen, ist es doch in Goethes Roman ein vom vermeintlichen Wahnsinn der unbedingten Liebe Gezeichneter, dessen gesammelte Briefe - ein der Tagebuchfiktion verwandtes Romangenre der subjektiven Erzählperspektive - seine geballte Verachtung der überlieferten Ordnung, der religiösen Orthodoxie und der politischen Kultur bezeugen, vor allem aber seine aus dem Geiste der Empfindsamkeit und des Subjektivismus gespeiste Rebellion gegen das herkömmliche Familien- und Eheideal. Gerade aber Werthers emotionsgeladener Einbruch ins geregelte Familien- und Eheleben wurde beim chinesischen Publikum offenbar empfunden als der ersehnte Protest gegen den Ahnen-, Familien-, und Ehekult der konfuzianischen Überlieferung, in der die Ideen der selbstbestimmten Partnerwahl oder gar der freien Liebe zurückzutreten hatten hinter dem Prinzip einer von Familie und Eltern bestimmten Eheschließung. Auch in China ist das Werther-Fieber, nicht anders als in Deutschland, das Symptom eines Generationskonflikts und des Protests der jungen Generation gegen eine - in diesem Fall konfuzianisch geprägte - „Rationalisierung“ der individuellen Bedürfnisse und ihrer „Sinnlichkeit“ (Gille 1998, 25-27; zu Guo Moruos marxistischer Goethe- und Faustdeutung vgl. im vorliegenden Band den Beitrag des Verfassers). 
Bereits 1917 hatte Chen Duxiu in der Zeitschrift Neue Jugend an die Autoren der Neue-Kultur-Bewegung die programmatische Frage gerichtet: „Ist unter unseren heldenhaften Literaten jemand da, der den Mut hat, ein Hugo oder Zola, ein Goethe oder Hauptmann, ein Dickens oder Wilde zu werden?“ (zitiert nach Wuneng 2000, 29). Um seinen Thesen zur ästhetischen Revolution einen konkreten Hintergrund zu geben, hat Chen 1918 in einer Sonderausgabe der Neuen Jugend Henrik Ibsens Drama Nora oder ein Puppenheim in einer modernen umgangssprachlichen chinesischen Übersetzung veröffentlicht, innerhalb der Literaturrezeption der Neue-Kultur-Bewegung desgleichen ein Schlüsseltext, noch weitaus wirkmächtiger als Goethes Werther. Ibsens Kritik am bürgerlichen Eheund Familienideal ließ sich, so legt es die Publikation in der Neuen Jugend nahe, ohne Schwierigkeiten übertragen auf die chinesischen Verhältnisse der brüchig werdenden konfuzianischen Ehe-, Familien- und Erziehungsordnung sowie ihrer strengen Männer-, Frauen- und Generationenbilder (Spence 1995, 389).

\section{Marx-Studien im Red Building, Marx in China}

Vergegenwärtigt man sich das Ausmaß und den leidenschaftlichen Ton der Überlieferungskritik bei Chen Duxiu, Lu Xun sowie Guo Moruo und fasst man die Kompromisslosigkeit ihres Protests gegen das alte China ins Auge - und die für diesen Protest charakteristischen, der deutschen Philosophie und Literatur entlehnten Argumente: Umwertung der Werte, Prometheismus, Sturm und Drang -, dann gewinnt man ein konkretes Bild von dem revolutionären Bruch in der chinesischen Geistes- und Kulturgeschichte, den die Aktivisten des 4. Mai 1919 und der NeueKultur-Bewegung vollzogen haben. Eben jener Bruch steht im Hintergrund der gewaltigsten „Transformationen“ und der in der Geschichte Chinas „noch nie dagewesenen strukturellen und ideologischen Umwälzungen“, von denen in dem eingangs erwähnten Katalog zur Ausstellung im Red Building die Rede ist.

$\mathrm{Zu}$ den hier präsentierten Originalen der Zeitschrift Neue Jugend, darin u. a. das Tagebuch eines Verrückten, die Thesen zur Literaturreform respektive zur Literaturrevolution und Ibsens Nora erschienen waren, zählt naturgemäß auch jenes Sonderheft der Neuen Jugend vom 1. Mai 1919, das Karl Marx und dem in China bis dahin weitgehend unbekannten - Marxismus gewidmet war. Als verantwortlicher Redakteur hatte dieses Heft Li Dazhao (1889-1927) konzipiert, seinerzeit Direktor der Bibliothek der Peking Universität, der desgleichen von Cai Yuanpei an diese Hochschule berufen worden war (Chow 1967, 53-55). Dort hatte Li bereits 1918 eine Studiengruppe ins Leben gerufen, die sich der systematischen Marx-Lektüre verschrieb. 


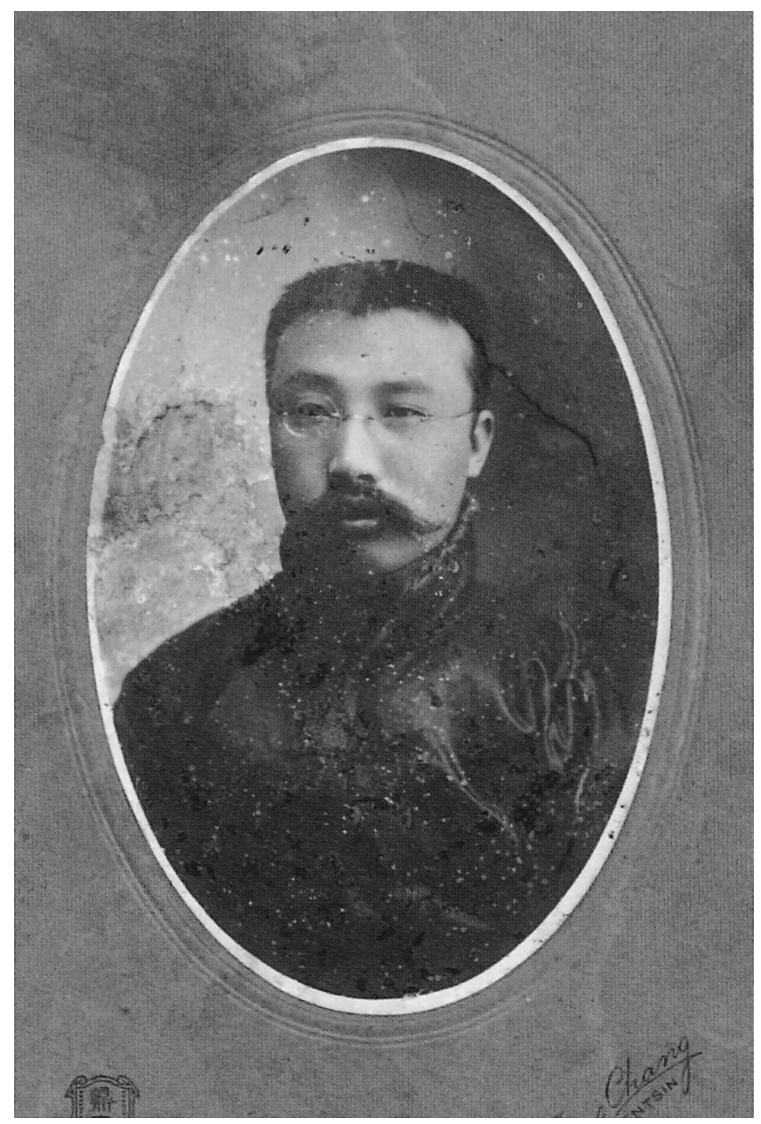

Abb. 14: Porträtbildnis von Li Dazhao.

An den Zusammenkünften nahm 1919 für einige Monate auch Mao Zedong teil, der seinem verehrten Lehrer Yang Changji - auch ihn hatte Cai Yuanpei an die Peking Universität berufen - in die Hauptstadt gefolgt war und während dieser Zeit als Hilfsbibliothekar im Zeitungslesesaal des Red Building arbeitete. Hier geriet er in unmittelbare Nähe jener Reform- und Revolutionsdebatten, die in der Redaktion der Neuen Jugend und unter den Autoren der Zeitschrift geführt wurden (vgl. Spence 2003, 56-63; Schmidt- Glintzer 2017, 55-59).

Wer heute die Ausstellung zum 4. Mai 1919 und zur Neue-Kultur-Bewegung im ehemaligen Universitätsgebäude besucht, dem öffnet sich ein Panorama auf den die geistige Situation dieser Zeit kennzeichnenden Zusammenhang von Sprach- und Literaturreform, Modernisierung, Kulturrevolution und politischer Revolution. Die erhaltenen Räumlichkeiten sowie die historisch gestalteten 


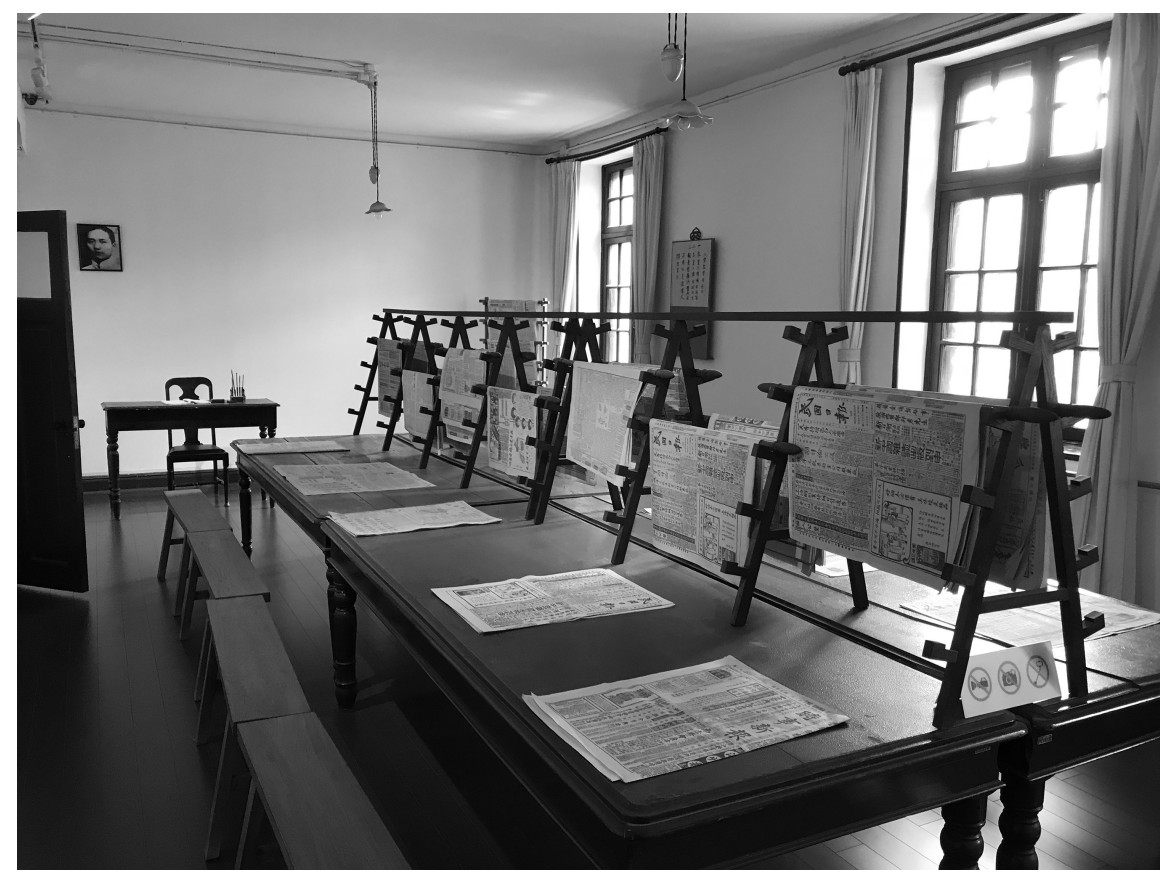

Abb. 15: Zeitungslesesaal im Red Building, in dem Mao für einige Monate als Hilfsbibliothekar gearbeitet hat.

Ausstellungssäle gestatten einen Blick in den Hörsaal, in dem Lu Xun über die Geschichte der chinesischen Erzählkunst las.

Es schließen sich im Erdgeschoss Bibliotheksräume, der Zeitungslesesaal und, neben dem bereits erwähnten Raum mit den Spruchbändern und Fahnen vom 4. Mai 1919, das Büro Li Dazhaos an, in dem sich die erste chinesische Marx-Studiengruppe versammelte. Im Vorgebäude der Universität wurde ein Museum zur Geschichte der Kommunistischen Partei Chinas eingerichtet, das jene im Red Building entstandene marxistische Linie der Neue-Kultur-Bewegung aufgreift und mit der maßgeblich von Chen Duxiu und Li Dazhao initiierten Gründung der KPCh 1921 in Shanghai einsetzt.

Verlässt man den Gebäudekomplex, befindet man sich auf der „Straße der Bewegung des vierten Mai“ und kann sich hier auf die historische Demonstrationsroute begeben, die dann weiter an der Ostseite der Verbotenen Stadt entlang zum Tian'anmen-Tor führt, vor dem sich die protestierenden Schüler und Studenten am 4. Mai 1919 versammelten und von dem aus dreißig Jahre später Mao Zedong am 1. Oktober 1949 die Gründung der Volksrepublik China proklamierte. 


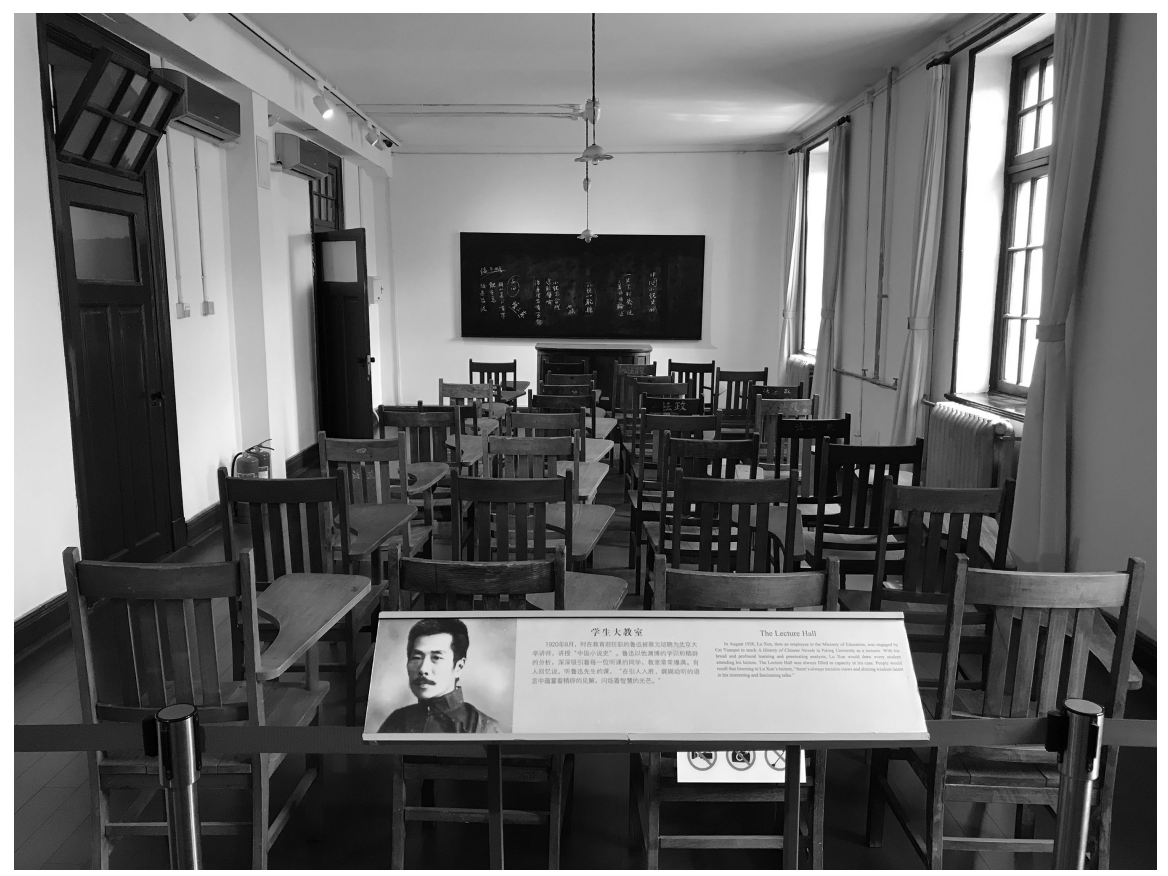

Abb. 16: Vorlesungssaal im Red Building, in dem Lu Xun unterrichtete.

Nirgends in China tritt der die Geschichte dieses Landes im 20. Jahrhundert auf so dramatische Weise prägende, spannungsvolle Kontrast zwischen Überlieferung und Moderne so konkret vor Augen wie an diesem Ort. Dem alten Kaiserpalast im Norden, mit seiner subtil gegliederten, das komplizierte System der alten kaiserlichen Riten abbildenden Struktur aneinandergereihter Höfe, Paläste und Gärten, liegt im Süden gegenüber die riesige, bis auf das Mao-Mausoleum und das Revolutionsdenkmal im Zentrum vollkommen leere Fläche des Tian'anmen-Platzes. Die auch hier ursprünglich noch erhaltene historische Bausubstanz des alten Peking war nach 1949 komplett abgebrochen worden, um Platz zu schaffen für die gewaltigen Aufmärsche, Paraden und Masseninszenierungen der Partei, deren Führung sich bei solchen Ereignissen auf der Balustrade des Tian'anmen-Tores versammelte.

Den scharfen horizontalen Gegensatz zwischen Überlieferung und Moderne, wie er sich im hochsymbolischen historischen und politischen Mittelpunkt Pekings zeigt, hat man in dem an der Ostseite des Tian'anmen-Platzes gelegenen chinesischen Nationalmuseum zu einem vertikalen Geschichtszusammenhang umgestaltet. 


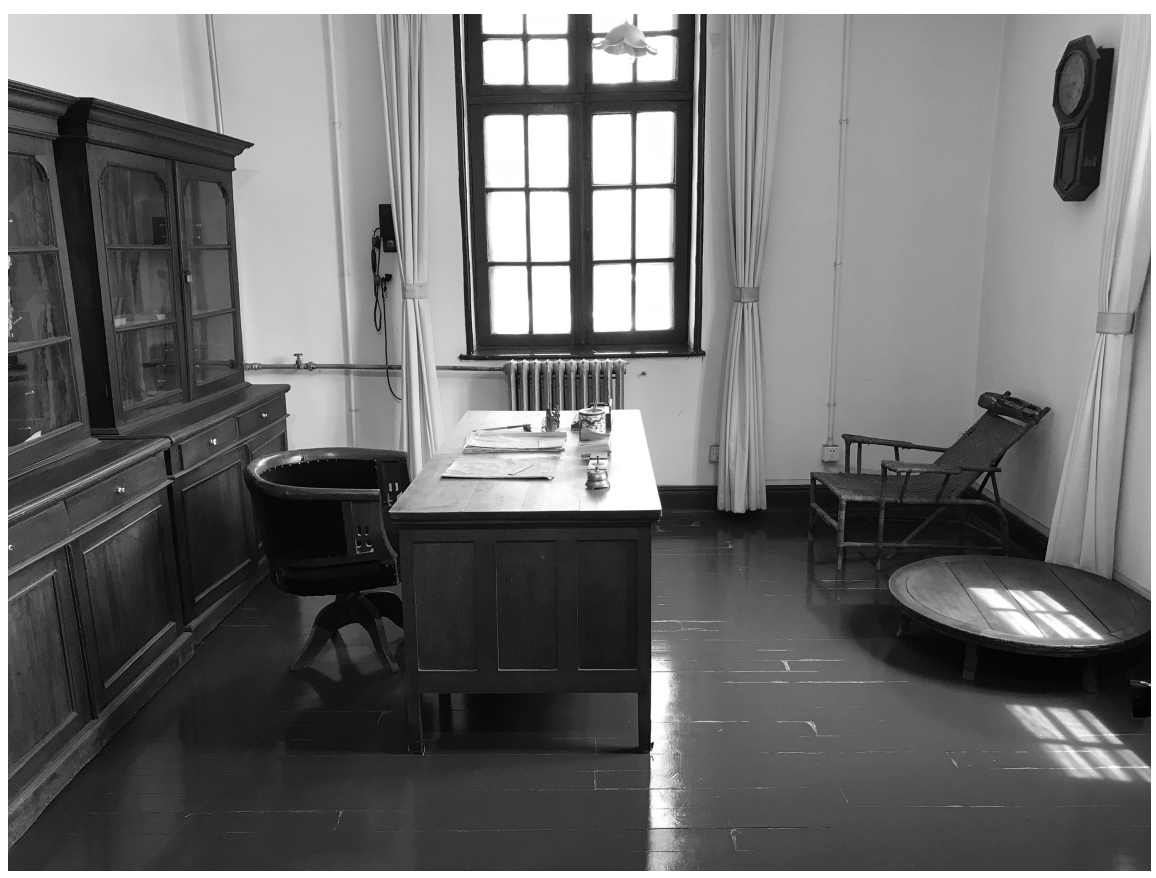

Abb. 17: Li Dazhaos Büro im Red Building.

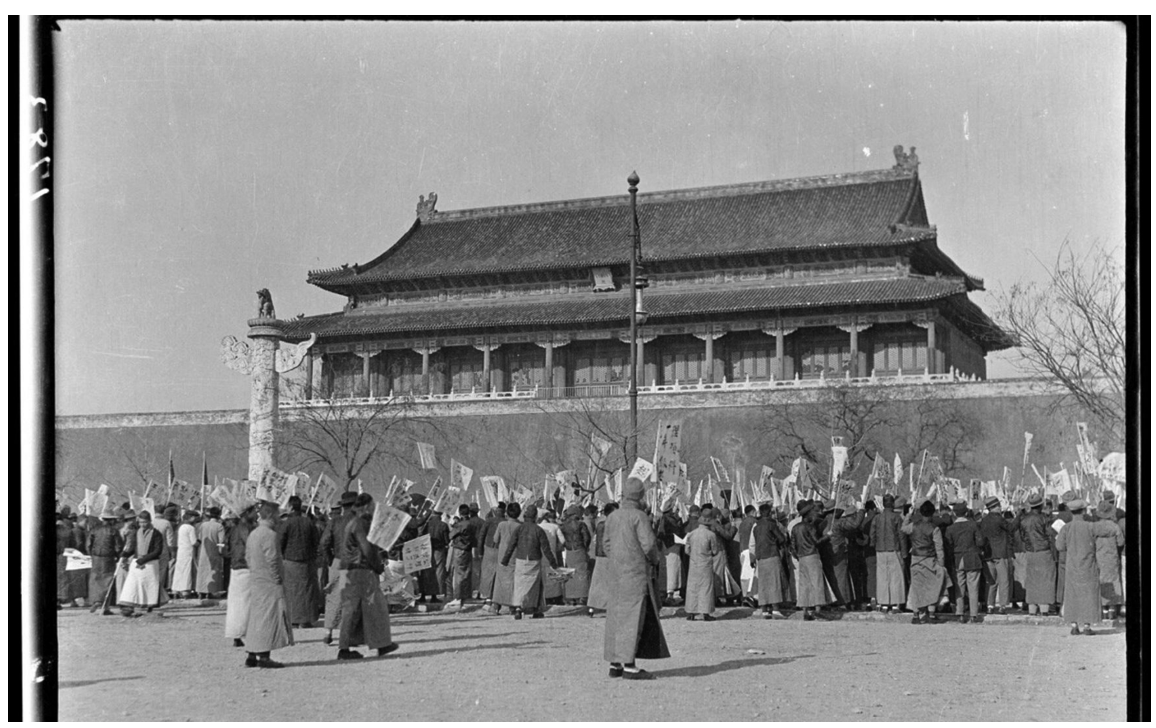

Abb. 18: Demonstrierende Studenten vor dem Tian'anmen-Tor im Jahr 1919. 


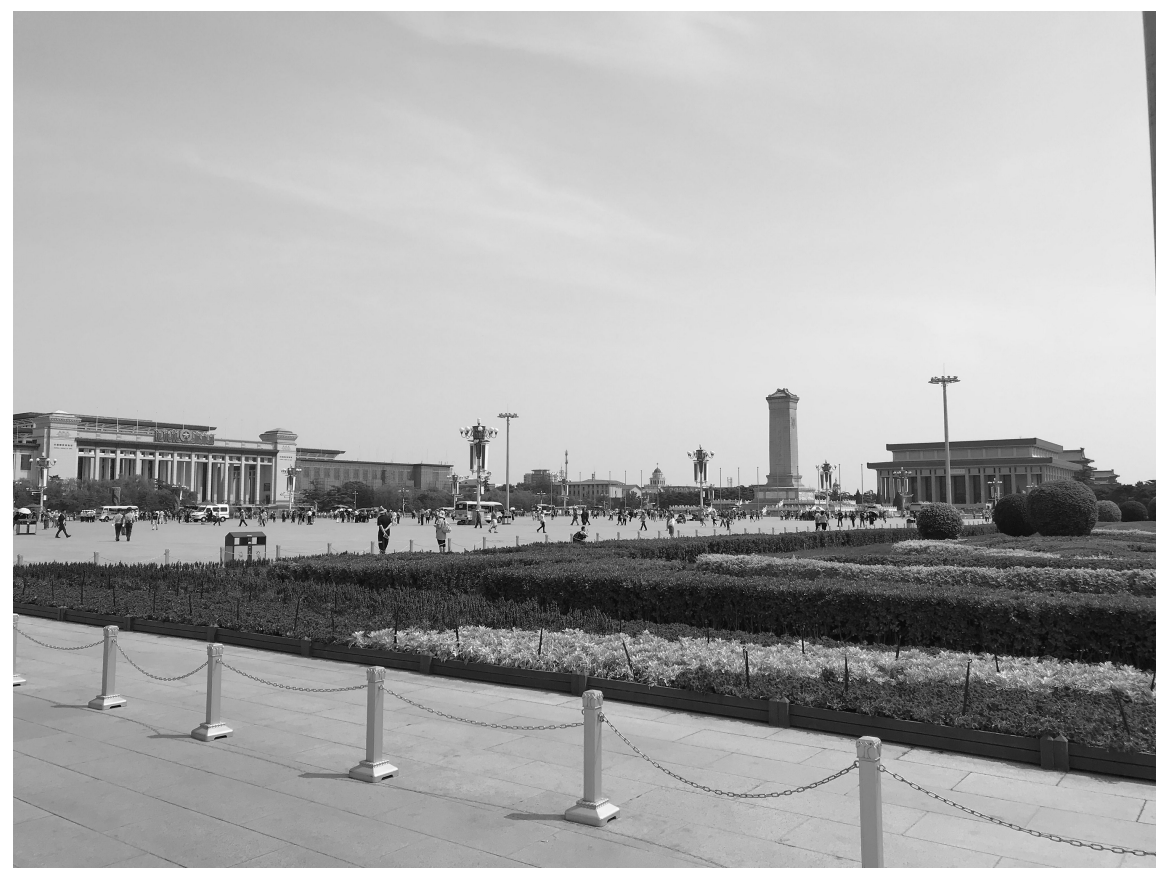

Abb. 19: Der Tian'anmen-Platz heute.

In der zu Beginn des 21. Jahrhunderts neu eingerichteten Ausstellung ruht die Moderne Chinas gleichsam auf dem Fundament seiner mehrtausendjährigen Geschichte, deren Epochen im Souterrain des kolossalen Gebäudes als Entwicklungsstufen eines historischen Ganzen präsentiert werden. Es gelangt, so die Leitidee der Ausstellung, während des 20. Jahrhunderts zu seiner wahren Bestimmung in der von der Kommunistischen Partei angeführten Revolution und in der darauffolgenden Gründung der Volksrepublik China. Diesen modernen Prozessetappen ist der riesenhafte zentrale Ausstellungssaal im Erdgeschoss vorbehalten, wo wir auf den die Wände ausfüllenden Monumentalgemälden einige der uns aus dem Red Building bekannte Aktivisten des 4. Mai und der Neue-Kultur-Bewegung wiedersehen: Guo Moruo etwa, in der zweiten Reihe hinter Mao Zedong, auf der Balustrade des Tian'anmen-Tores bei der Ausrufung der Volksrepublik, und Lu Xun, dessen überlebensgroße Bronzeplastik unmittelbar neben dem Tableau der Proklamation vom 1. Oktober 1949 aufgestellt wurde.

In der parteioffiziellen Jubiläumsausstellung, die im Jahr 2018 im Nationalmuseum anlässlich des 200. Geburtstages von Karl Marx gezeigt wurde („The Power of Truth. The Life and Works of Marx"), fehlte an prominenter Stelle nicht 


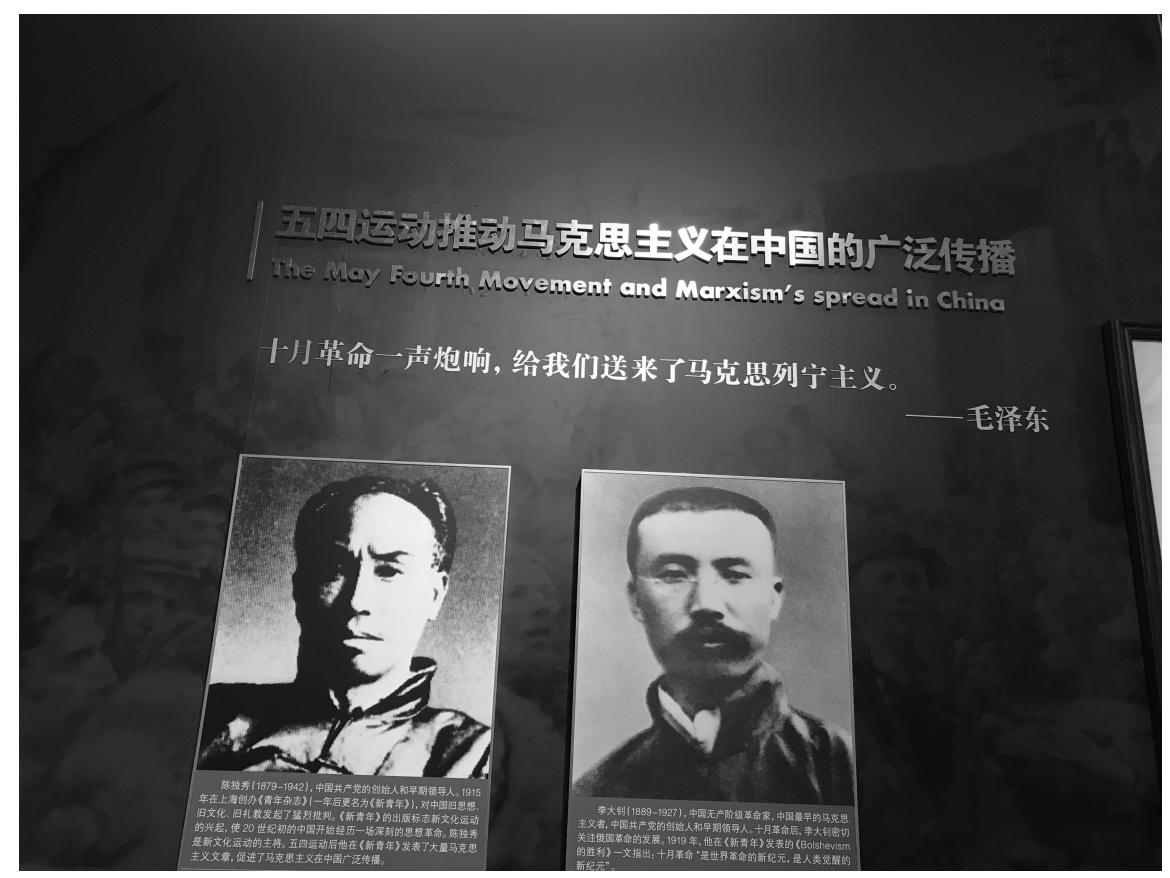

Abb. 20: Chen Duxiu und Li Dazhao in der Ausstellung zum 200. Geburtstag von Karl Marx im chinesischen Nationalmuseum.

die Erinnerung an Chen Duxiu und Li Dazhao, die man hier unter dem Motto vereinigt hatte: „The May Fourth Movement and Marxism’s spread in China“.

So ließ sich die Pekinger Marx-Ausstellung verstehen als höchst eindrucksvolle Illustration jenes im Umkreis der 4.-Mai-Bewegung stattfindenden deutschchinesischen Ideenaustausches, als dessen definitiv wirkmächtigster Anteil sich in der Folgezeit zweifellos die chinesische Marx-Rezeption entwickelte. Die Exponate vermittelten einen konkreten Eindruck von dem in kaum fassbarer Direktheit die Kontinente und Kulturen überquerenden Ideentransfer. Historische, auf den ersten Blick doch wohl provinzielle Szenen und Familienbilder aus Marx' südwestdeutscher Heimatstadt Trier etwa, zahlreiche Briefe aus seiner Hand sowie Originalmanuskripte und Marx' Artikel in deutschen Zeitungen und Zeitschriften jener Epoche nahmen an diesem Ausstellungsort eine frappierend welthistorische Bedeutung an.

Noch viel erstaunlicher wirkten auf die Besucher die ausgestellten Schriften von Marx samt ihrer (mehrfachen) chinesischen Übersetzungen. Um nur ein Beispiel herauszugreifen: Im Zentrum Pekings in chinesischer Fassung Marx' Kritik an den Beschlüssen einer sozialdemokratischen Parteiversammlung zu sehen, die 
1875 in der thüringischen Kleinstadt Gotha stattgefunden hat, das öffnete - eingedenk der unmittelbaren Konsequenzen, die der auf das „Gothaer Programm“ gemünzte Marx-Text in der politischen Realität Chinas haben konnte - für einen Moment die atemberaubende Sicht auf den globalen Charakter des Modernisierungsprozesses im 20. Jahrhundert.

Der einleitende Rückblick auf einige Aspekte des 4. Mai 1919, den man als eines der Schlüsselereignisse im Jahrhundert der Extreme verstehen wird, lässt sich mit Bildern vom Frühsommer 2018 schließen, als anlässlich des 120. Jahrestages der Gründung der Peking Universität Präsident Xi Jinping - selbstredend war es der 4. Mai 2018! - die Hochschule besuchte. Naturgemäß begab er sich dort in die renommierte „School of Marxism“, als deren historischer Ur-

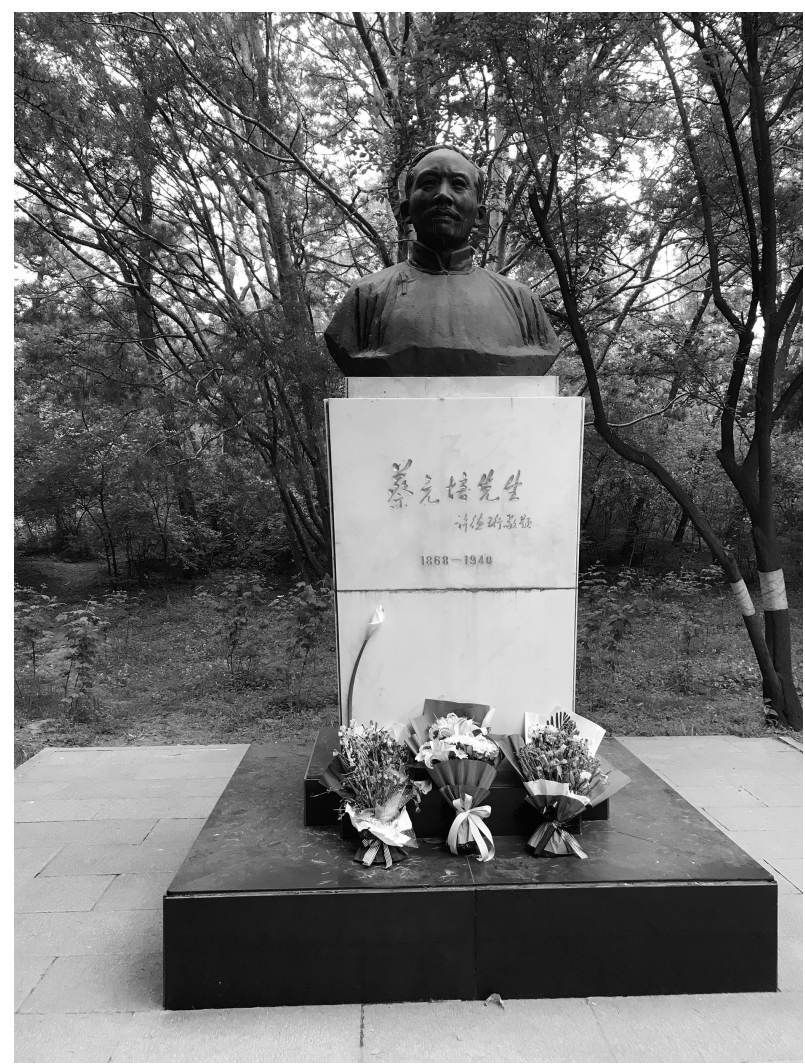

Abb. 21: Blumen vor Cai Yuanpeis Denkmal auf dem Campus der Peking Universität. 
sprung mit guten Gründen jene Marx-Lektüregruppe gelten kann, die sich erstmals 1918 in der Bibliothek des Red Building versammelte.

Nicht weit entfernt von der „School of Marxism“ steht auf dem jetzt im Nordwesten Pekings gelegenen, parkartigen Gelände der Peking Universität das Denkmal Cai Yuanpeis. Cai trat seit den zwanziger Jahren des vergangenen Jahrhunderts als dezidierter Kritiker aller radikalen Revolutionsprogramme auf. Heute liegen vor seinem Denkmal, das sich in einer im Stil der traditionellen chinesischen Gartenkunst gestalteten Anlage befindet, stets frische Blumen.

\section{Deutsche China-Faszination und der paradoxe chinesisch-deutsche Dialog}

Schaut man auf den chinesisch-deutschen Ideenaustausch in einer vergleichenden Perspektive, so zeigt die wechselseitige Wahrnehmung der beiden Länder zu Beginn des 20. Jahrhunderts einen auffällig paradoxen Verlauf. In China ist es gerade die Kritik an der eigenen Überlieferung - vor allem am traditionellen Bildungskanon und am strengen Ordnungs- und Hierarchiedenken des Konfuzianismus -, die das Interesse der jüngeren Generation an der deutschen Philosophie und Literatur befördert. Beim deutschen Part jenes Dialogs der beiden Kulturen wird man hingegen zur gleichen Zeit ein ausgeprägtes Interesse an eben derselben chinesischen, insbesondere konfuzianischen und daoistischen Tradition und ihrer Literatur bemerken, die in der Perspektive der Bewegung des 4. Mai in China der kritischen, mitunter auch hochpolemischen Ablehnung anheimfällt. Die Bibliothek der Peking Universität bewahrt zahlreiche Dokumente dieser deutschen Rezeption der chinesischen Literatur zu Beginn des 20. Jahrhunderts auf. Eine Ausstellung der Universitätsbibliothek präsentierte im November 2014 reichhaltiges Material dazu. Insbesondere die Übersetzungen der klassischen chinesischen Dichtung von Richard Wilhelm, Vincenz Hundhausen und Franz Kuhn, während der 1920er Jahre in Deutschland vor allem im Insel-Verlag in Leipzig und im Eugen-Diederichs-Verlag in Jena erschienen, wären hier zu nennen. Zahlreiche Exponate waren mit den zeitgenössischen Stempelzeichen „Bibliothek des Deutschland-Instituts Peking“, „Pekinger Verlag, Peking-Leipzig“, „Deutsche Vereinigung Peking“ versehen.

Die deutschen Übersetzungen der chinesischen Klassiker sowie die zeitgenössische deutsche China-Literatur wird man als typischen Ausdruck für die nach dem Ersten Weltkrieg in Deutschland zunehmende Faszination der Philosophie und Literatur des „Ostens“ ansehen können. Dahinter steht bei den deutschen Autoren dieser Zeit eine dialektisch-ambivalente und kritische Erfahrung der Mo- 
derne (zu literarisch-journalistischen Chinainszenierungen in Deutschland zwischen 1920 und 1930 im Spannungsfeld von Tradition und Moderne vgl. im vorliegenden Band den Beitrag von Almut Hille). Wird also die Rezeption der deutschen Literatur in China bei der jungen chinesischen Generation und bei den Protagonisten des „Vierten Mai“ vor allem befördert von einer Krise der chinesischen Tradition, so inspiriert auf deutscher Seite in der Folge der Weltkriegserfahrung die desillusionierende Bewertung des Modernisierungsprozesses - des technischen Fortschritts und der instrumentellen Vernunft - das Interesse an eben derselben klassischen chinesischen Überlieferung und ihrer Literatur (vgl. dazu im vorliegenden Band den Beitrag von Huang Chaoran zu Hermann Hesses Wahrnehmung der chinesischen Kultur und ihrer Geschichte). Der chinesisch-deutsche Dialog scheint daher während der ersten Jahrzehnte des 20. Jahrhunderts im Zeichen paradoxer Modernitätserfahrungen und Modernitätshoffnungen zu stehen und als solcher die epochentypischen intellektuellen und literarischen Reaktionsweisen, Debatten und Widersprüche abzubilden.

\section{Literaturverzeichnis}

Chang, Jung, und Jon Halliday. Mao. Das Leben eines Mannes, das Schicksal eines Volkes. München 2007.

Chow, Tse-tsung. The May Fourth Movement. Intellectual Revolution in Modern China. Stanford 1967.

Ess, Hans van. Der Konfuzianismus. München 2009.

Franke, Wolfgang. Chinas kulturelle Revolution. Die Bewegung vom 4. Mai 1919. München 1957.

Gille, Klaus F. Zwischen Kulturrevolution und Nationalliteratur. Gesammelte Aufsätze zu Goethe und seiner Zeit. Berlin 1998.

Gu, Xuewu. Konfuzius zur Einführung. Hamburg 1999.

Höllmann, Thomas O. Die chinesische Schrift. Geschichte, Zeichen, Kalligraphie. München 2015.

Kubin, Wolfgang (Hrsg.). Nachrichten von der Hauptstadt der Sonne. Moderne chinesische Lyrik. 1919-1984. Frankfurt am Main 1985.

Lawrance, Alan. China Since 1919 - Revolution and Reform. A Sourcebook. London 2004.

Lu, Xun. „Das Tagebuch eines Verrückten“. Werke. Hrsg. Wolfgang Kubin. Band II. Zürich 2015. $16-32$.

Old Nation New Mission. An Exhibition Marking the Centenary of the New Culture Movement. Beijing 2016.

Marx, Karl, und Friedrich Engels. „Manifest der Kommunistischen Partei“ (1848). Marx Engels Werke (MEW). Band 4. Berlin 1959. 458-493.

Schmidt-Glintzer, Helwig. Mao Zedong. „Es wird Kampf geben“. Eine Biografie. Berlin 2017. Schmidt-Glintzer, Helwig. Kleine Geschichte Chinas. München 2008. 
Schmidt-Glintzer, Helwig. Geschichte der chinesischen Literatur. Von den Anfängen bis zur Gegenwart. München 1999.

Spence, Jonathan. Mao. München 2003.

Spence, Jonathan. Chinas Weg in die Moderne. Aktualisierte und erweiterte Ausgabe. München 2001.

Steensen, Thomas (Hrsg.). Friedrich Paulsen. Weg, Werk und Wirkung eines Gelehrten aus Nordfriesland. Husum 2010.

Yang, Wuneng. Goethe in China (1889-1989). Frankfurt am Main 2000.

\section{Bildquellen}

Abbildungen 1, 5, 8

Abbildungen 2, 4, 9, 15, 16, 17, 19, 20, 21

Abbildung 6

Abbildungen 3, 7, 8, 10, 11, 12, 13, 14
Sidney D. Gamble photographs, David M. Rubenstein Rare Book \& Manuscript Library, Duke University

Bildarchiv von Michael Jaeger

Wikipedia

Lu Xun Museum (Beijing New Culture Movement Memorial) 
